\title{
The effects of increasing the normal retirement age on health care utilization and mortality
}

\author{
Johannes Hagen ${ }^{1,2}$ (iD
}

Received: 2 November 2016 / Accepted: 8 August 2017 / Published online: 24 August 2017

(C) The Author(s) 2017. This article is an open access publication

\begin{abstract}
This essay estimates the health effects of increasing the normal retirement age using Swedish administrative data on drug prescriptions, hospitalizations, and mortality. To this end, I use a reform that raised the age at which broad categories of Swedish local government workers were entitled to retire with full pension benefits from 63 to 65 . Estimating the effect of the reform on individuals' health within the age range 65-69, the results show no evidence that the reform impacted mortality or health care utilization. Increasing the normal retirement age may thus have positive government income effects without seriously affecting short to medium run government health care expenditures.
\end{abstract}

Keywords Health $\cdot$ Mortality $\cdot$ Inpatient care $\cdot$ Retirement $\cdot$ Pensions

JEL Classification I18 $\cdot$ J22 $\cdot$ J26

\section{Introduction}

Many countries have responded to increasing life expectancy by raising retirement age thresholds while others have announced future increases. ${ }^{1}$ The key rationale for

\footnotetext{
${ }^{1}$ See, e.g., Feldstein and Siebert (2009) and Holzmann (2005) for a discussion of recent pension reforms around the world and Andersen et al. (2014) for a focus on the Nordic countries.

Responsible editor: Alessandro Cigno

Johannes Hagen

johannes.hagen@nek.uu.se

1 Department of Economics, Uppsala University, Box 513, 75120 Uppsala, Sweden

2 Present address: Jönköping International Business School, Jönköping University, Jönköping, Sweden
} 
such reforms is to improve the fiscal stability of pension systems through increased labor force participation rates among older workers. However, critics argue that the positive consequences must be weighed against the potential adverse effects of working longer on health. If workers are unable to work until the raised retirement age or if their health deteriorates at a faster rate due to continued work, the fiscal burden might simply be shifted from the pension system to other parts of the welfare system. Understanding the health effects of retirement age increases, in conjunction with longer working lives, is therefore a crucial issue in pension policy design.

This paper studies the consequences of a 2-year increase in the normal retirement age for Swedish local government workers on subsequent health. Prior to year 2000 , these workers could retire at age 63 with full pension benefits and an average replacement rate of $73 \%$. As of 2000 , those born before 1938 could continue to retire under the old rules, but those born in or later than 1938 had to work until the age of 65 to claim a full benefit. The new rules incentivized these workers to retire later as each month of retirement before age 65 implied a benefit reduction of $0.4 \%$. The reform caused a remarkable shift in the retirement distribution, increasing the actual retirement age by more than 4.5 months. The effect of the reform is estimated by examining their subsequent health in ages 65-69.

The identification strategy is based on cohort variation in the timing of the reform, and as health measurements, I use drug prescriptions, hospitalizations, and mortality. The main analysis makes use of the cohorts born 1938-1942 who were fully affected by the reform and the cohorts born 1935-1937, who were not affected, in the estimation of the counter-factual health of those born 1938-1942. Because there were very few men in the affected worker categories, the analysis focuses exclusively on women. I use female private sector workers of the same ages who were not affected by the reform to control for general period effects. The control group experienced no major change in retirement incentives during the period of study and are similar to the local government workers along several background covariates. Estimation is thus performed using difference-in-difference regression models, which also allow me to control for pre-reform characteristics of the individuals.

The results show no effect on the probability of being prescribed a non-zero quantity of drugs, nor on total drug purchase. There is also no effect on the probability of being hospitalized due to any cause, nor on the number of days spent in hospital. Moreover, tracking mortality up to age 69, I fail to reject the null hypothesis of no causal effect of working longer on mortality. The estimates are precisely estimated, which allows me to bound the effect sizes to a narrow range around zero.

Although the empirical framework is based on Swedish public sector workers, the results should be of more general interest. First, data from the European Union Labour Force Survey show that the occupations of interest, including personal care workers, nursing professionals, cleaners, and restaurant service workers, belong to the most common occupations for women both in Sweden and abroad. Second, the focus on low- to medium-paid public sector jobs is relevant from a policy perspective since various discussions of increasing the retirement age thresholds deal primarily with the concern that such increases could adversely affect individuals in low-skilled jobs. The abovementioned occupations are characterized by demanding work environment and relatively high rates of sickness absence. Third, since retirees have equal 
access to publicly provided health service and medical care as employed individuals, the estimates are likely to capture the direct effect of the retirement age increase on health care utilization and mortality, rather than indirect effects, such as access to health insurance. The effects are also unlikely to operate through a loss of income as the long-run effect of the reform on disposable income is small. Finally, health care utilization is arguably the most important health dimension in estimating the fiscal impact of reforms that promote longer working lives. In 2014, individuals aged 65 and over comprised $20 \%$ of the Swedish population, but they accounted for $40 \%$ of total drug prescriptions and $47 \%$ of all patient discharges from public hospitals (Socialstyrelsen 2015a, b).

The remaining part of the paper is organized as follows. Section 2 discusses the previous literature, Section 3 discusses the details of the reform, Section 4 describes the methodological framework and the data, Section 5 provides the analysis, and Section 6 concludes.

\section{Previous literature}

Empirically investigating the causal effects of retirement on health is a difficult task because the retirement decision is endogenous to health. Workers in good health are more likely to retire late, meaning that the simple correlation between health and retirement is likely to be positive. To properly assess the effect of retirement itself on health, we need independent variation in retirement timing. The most frequently used instrument is age-specific retirement incentives, such as early retirement windows or eligibility age thresholds. This strategy has been used both in cross-country studies (e.g., Rohwedder et al. 2010; Sahlgren 2012; Heller-Sahlgren 2017; Mazzona and Peracchi 2012, 2017; Coe and Zamarro 2011; Godard 2016) and in within-country studies (e.g., Charles 2004; Bound and Waidmann 2007; Neuman 2008; Bonsang et al. 2012; Gorry et al. 2015; Behncke 2012). The identifying assumption is that the instruments affect health only indirectly through their effects on the age of retirement. This is a strong assumption for several reasons. First, workers who anticipate that there are financial incentives to retire at a certain age may adjust their behavior before retirement (Coe and Lindeboom 2008). Second, absent any behavioral response, workers who are subject to different retirement rules may differ with respect to unobserved variables (Kuhn et al. 2010). For example, individuals with a bad latent health state might be more likely to choose jobs where they can retire early. Third, reaching the eligibility age or the normal retirement age may have a direct impact on health if it is considered a milestone in a person's life (Behncke 2012).

Researchers have turned to reform-based variation in retirement timing to deal with these issues. Comparing individuals affected by a reform to individuals who are not means that we do not have to worry about the underlying reasons why individuals chose their respective occupation in the first place. This approach also overcomes the issue of individuals adjusting their behavior before retiring, provided that the reform is not fully anticipated by the individuals. The reform studied in this paper was announced only 1 year prior to its implementation, therefore giving workers little opportunity to increase their retirement income in ways other than retiring later. 
A number of studies have used variation from reforms that make early retirement more attractive. The general result from these studies suggests that increasing the retirement age would contribute to a deterioration in population health. ${ }^{2}$ However, such generalizations may be misleading if the potential effects of a change in the actual retirement age due to an increase in the retirement age are different from the corresponding effect that follows from lowering the earliest eligibility age. Early retirement reforms often contain elements of involuntary retirement, which makes it difficult to separate the potential effects of the reform itself from those of a change in the actual retirement age. They also target select groups of workers in industries or occupations in need of re-structuring.

The evidence from reforms that promote longer working lives is more scarce. While reforms that promote early retirement typically were introduced in the 1970s and 1980s, reforms that promote longer working lives were introduced after the 1990s. Atalay and Barrett (2014) exploit variation across birth cohorts in the eligibility age for women from the Australian 1993 Age Pension reform and find that retirement has a positive impact on health. Lalive and Staubli (2015), on the other hand, find no strong evidence of an effect on mortality from a Swiss reform that raised women's full retirement age from 62 to 64 . This study contributes to this literature by using administrative data on both cause-specific mortality and the utilization of health care.

The reform-based approach has also been subject to critique. One critique is that the approach potentially captures other things than the "pure" effect of retirement on health. For example, a change in the pension system's rules close to retirement might impact health before the individual retires (de Grip et al. 2012). In the context of this paper, raising the normal retirement age with short notice might have been perceived as unfair, which may have impacted (mental) health negatively. However, the new retirement age for the affected workers was already the normal retirement age in all other occupational pension plans, both in the public and private sector. This should have played down feelings of disappointment and frustration among the affected local government workers. Nonetheless, the intention-to-treat effects will inevitably capture a combined effect of working longer and of having retirement plans change unexpectedly due to the policy.

Another potential problem with the reform-based approach, if our aim is to estimate the effects of retirement on health, is that pension reforms might have limited effects on retirement behavior. The smaller the retirement response, the less likely we are to detect economically significant effects on health. Given the findings in the literature on the retirement effects of pension age increases, the estimated 5-month increase in the actual retirement age from a 2-year increase in the formal retirement age is in the lower bound of the expected range. ${ }^{3}$ Now, 5 months of additional work is

\footnotetext{
${ }^{2}$ Coe and Lindeboom (2008), Bloemen et al. (2013), and Hallberg et al. (2015) find that (early) retirement is associated with an improvement in well-being. An exception is Kuhn et al. (2010), who find that access to more generous early retirement rules increased mortality among male blue-collar workers in Austria.

${ }^{3}$ For example, Mastrobuoni (2009) and Song and Manchester (2007) show that the labor force exit in the USA amount to about half the age increase. Hanel and Riphahn (2012) and Lalive and Staubli (2015) show that the Swiss 2-year increase delayed women's average exit by 7.7 months.
} 
not small compared to the other reform-based studies discussed above. And the fact that we focus on additional work close to the normal retirement age, as opposed to the earliest eligibility age, among workers in both physically and mentally demanding occupations, also suggest that meaningful effects on health could be detected. Note, however, that even absent any retirement response, it is relevant from a policy perspective to estimate the health effects of retirement age increases. The effects on health could, e.g., operate via lower lifetime income. The potential income effects of the reform studied in this paper are investigated in Section 5.3.

This paper relates more broadly to a literature that tries to estimate the causal effect of retirement on health. To get a picture of the results in this literature, Table 12 gives a brief summary of the empirical methods and key findings of 26 selected articles in the health-economic literature. Two of these studies report zero effects of retirement. Thirteen studies report that retirement has a positive effect on health, whereas the remaining eleven conclude that retirement is in fact associated with a decline in health. That research finds mixed results reflects the underlying theoretical ambiguity about the sign of the effect. On the one hand, new retirees may lose some incentive to invest in their health, as their income is no longer dependent on health. Retirement might also lead to a general decline in physical activity if work constitutes the primary form of exercise. On the other hand, retirees have more leisure time with which to engage in physical activity or healthier diets, and are also relieved from work-related physical strain. The net effect of retirement on mental health is also difficult to predict. Retirement might have a positive impact on mental health through increased sleep duration (Eibich 2015; Vahtera et al. 2009) and diminished work stress (Midanik et al. 1995) but could also increase social isolation and depression (Börsch-Supan and Schuth 2014; Dave et al. 2008; Heller-Sahlgren 2017). Even though these papers differ along several important dimensions, such as the population being studied, health outcomes and empirical methodology, these contrasting results are also likely to stem from the lack of convincing empirical strategies to deal with endogenous selection into retirement.

\section{The occupational pension system}

\subsection{Retirement benefits in Sweden}

Sweden's pension system has two main pillars, a universal public pension system and an occupational pension system. Swedish retirees generally receive most of their pension income from the public pension system, but the occupational pension system is an important complement. The occupational pension system consists of a number of different pension plans that are negotiated at the union level and cover large group of workers. In fact, the four largest agreement-based occupational pension plans cover around $90 \%$ of the total work force. These include the pension plan for blue-collar private sector workers, white-collar private sector workers, local government workers, and state-level government workers, respectively. The focus of this study is the pension plan for local government workers. 


\subsection{The occupational pension reform for local government workers}

The pre-reform occupational pension plan for local government workers, called PAKL, covered local government workers born before January 1, 1938. PA-KL was defined benefit and directly coordinated with the public pension system. PA-KL stipulated that the sum of the annual occupational pension benefit and the public pension benefit should amount to a certain fraction of the individual's pre-retirement income. The occupational pension would always pay out the residual amount net of the public pension benefit to reach a certain replacement rate. In year 2000, the gross replacement rate amounted to $73 \%$ for a female local government employee with an average wage rate who retired at the age of 63 . If the public pension accounted for $60 \%$, the occupational pension benefit would amount to $13 \%$ of her qualifying income. Thus, local government workers only needed to know about the gross replacement rates to get a full picture of their retirement income. ${ }^{4}$

In the pre-reform pension plan, the age at which full or unreduced retirement benefits could be withdrawn, i.e., the normal retirement age (NRA), was different for different occupations. The NRA was either 63 or 65 . Early withdrawals could be made from the age of 60 , but the penalty rate at a given claiming age, i.e., the reduction in the gross replacement rate, was different depending on what NRA the worker faced. Here, I focus on workers who had a NRA of 63.

Workers who faced a NRA of 63 could retire at this age with a full benefit. The benefit was not actuarially increased for claims made after 63 , which means they had little incentive to work past this age. Selin (2017) shows that an individual with median earnings who chose to work an additional year at age 63 lost benefits amounting to $71 \%$ of the current wage after discounting (the benefit accrual). In comparison, a private sector worker of similar age and with similar earnings faced a positive accrual rate of $10 \%$. Broad categories of workers had a NRA of 63 , including personal care workers, nurses, pre-school teachers, restaurant service workers, and cleaners.

In 1998 a new agreement, PFA98, was signed for Swedish local government workers. The most important change was that the NRA was set to 65 for all local government workers. This was achieved by introducing equal early retirement penalty rates for all occupations. The new penalty rates implied that the pension was reduced by $0.4 \%$ per month of retirement before age 65 . Rather than receiving a full benefit, retiring at age 63 as compared to 65 now implied a substantial benefit reduction of $9.6 \%(0.4 * 12 * 2=9.6)$.

The reform implied a partial shift from defined benefit to defined contribution. ${ }^{5}$ This meant that the individual could always increase her pension wealth by postponing retirement until the age when she was obliged to retire or until no more pension

\footnotetext{
${ }^{4}$ Selin (2017) has used this reform to study spousal spillover effects on retirement behavior.

${ }^{5}$ For earnings below the ceiling of 7.5 increased price base amounts, the pension was entirely defined contribution. 1 increased price base amount equaled SEK 43,300 in 2010. The contribution differed slightly over time and also between employers and type of tenure, but centered on $3.4-3.5 \%$ for wage portions below the income ceiling and $1-1.1 \%$ for earnings above. Individuals with earnings above the ceiling got an additional defined benefit pension. This defined benefit component amounted to $62.5 \%$ of earnings between 7.5 and 20 base amounts and $31.25 \%$ between 20 and 30 base amounts
} 
rights could be earned. The shift was part of a general trend in favor of defined contribution systems. Thus, when the public pension system was reformed, see Section 3.3 below, it was natural to adjust the rules of the pension plan for local government workers as well.

While the reform substantially increased the incentives to postpone retirement beyond the age of 63 , it did not change the stock of already accumulated occupational pension wealth. The reason for this was a transition rule that would compensate workers in post-reform cohorts for potential benefit reductions due to the new rules. The pension wealth earned up to December 31, 1997, was converted into a life annuity that corresponded to the annual pension benefit that the individual would have received if she had retired by that date. Pension rights earned after this date were accredited the new pension plan. If the resulting pension from these two components was lower than the corresponding pension in the absence of a reform, workers received the difference from the employer. As a result, the pension wealth at age 65 was more or less unchanged for the transition cohorts. Importantly, workers who retired before 65 were not eligible for this compensation, which implies that the most important effect of the reform was to raise the NRA from 63 to 65 for workers who had a NRA of 63 in the pre-reform pension plan. Naturally, the transition rule also implied that the new DC component became relatively more important for younger cohorts.

The new PFA98 agreement came into effect on January 1, 2000, for those born in 1938 or later. Those born in 1937 and earlier were completely unaffected by the occupational reform and would still be covered by the old plan. The reform was implemented rather quickly and without much media coverage. ${ }^{6}$ Local government workers could avoid the new rules by retiring prior to the implementation of the new pension plan on January 1, 2000. Given that the reform was agreed on in mid-1998, those born in 1938 and 1939 were given some room to retire under the old rules.

\subsection{The public pension system and private sector pension plans}

The first post-reform cohort in the empirical analysis, i.e., those born in 1938, are also the first cohort to participate in the new public pension system. The new system is notional defined contribution (NDC) and has been described by, e.g., Sundén (2006). The 1938 cohort receives one fifth of its benefit from the new system and four fifths from the old system. Each cohort then increases its participation in the new system by 1/20, so that those born in 1954 will participate only in the new system (Hagen 2013). Thus, the differences in financial incentives between adjacent cohorts are relatively small due to the gradual phase-in of the new pension system. Benefits from the new system were paid out for the first time in 2001, 3 years after it was legislated.

\footnotetext{
${ }^{6}$ Selin (2017) reports that a search in the online press archive Presstext, which covers the biggest daily newspapers in Sweden, reveals that the first article mentioning PFA98 is written in the fall of year 2000. Low media coverage, however, does not rule out the possibility that the reform may have become known among the affected individuals through unions informing or word-of-mouth information.
} 
The 1938 cohort was also the first to be affected by the 2001 increase in the mandatory retirement age. Before 2001, most central agreements between trade unions and and employers' associations had a stipulated retirement at the 65th birthday. Workers could work past this age, but only if the employer approved. From 2001, mandatory retirement ages below 67 were no longer allowed to be agreed on. The new legislation affected both private and public sector employees and there seem to have been very small effects of the reform on labor force participation rates (Laun and Palme 2017). This reform could, however, have affected the long-term trend towards increased labor force participation of 65-69-year-old females.

The control group is made up of private sector workers. There are two large occupational pension plans in the private sector: one for blue-collar workers (SAF-LO) and one for white-collar workers (ITP). The ITP plan was mainly defined benefit and the same rules applied to all birth cohorts studied in this paper. The SAF-LO plan, on the other hand, is a pure defined contribution scheme. The implementation of the SAF-LO plan in 1996 implied that blue-collar workers born between 1932 and 1967 were subject to special transitional rules. However, cross-cohort differences in retirement incentives are minor because of the long transition period. Importantly, all private sector workers in the relevant birth cohorts faced a normal retirement age of 65 .

\section{Methodological framework, data, and sampling}

\subsection{Methodological framework}

The interest is in estimating the effects of the reform that raised the normal retirement age of those born in 1938 or later from 63 to 65 . The measurements of health are drug prescriptions, hospital admissions, and mortality. I use the 1935-1937 cohorts to estimate the counter-factual health of those born 1938-1942. To take into account the potential differences in health at a given age across cohorts, I make use of female private sector workers in the same birth cohorts to estimate the potential cohort effect. Thus, for individual $i$ in cohort $j$ in sector $s$, the estimated difference-in-difference equation is written as:

$$
y_{i, j, s}=\alpha+\delta\left(L G_{s} \times C H_{j \in[1938,1942]}\right)+\phi L G_{s}+\lambda_{j}+\mathbf{X}_{i, j, s} \theta+u_{i, j, s}
$$

where $y_{i, j, s}$ is a health outcome, $\lambda_{j}$ denotes cohort-fixed effects and the vector $\mathbf{X}_{i, j, s}$ is a set of control variables which include years of schooling, earnings, and previous sickness absence (see Table 4 for a complete list of controls). $L G_{s}$ and $C H_{j \in[1938,1942]}$ are dummy variables that equal 1 if individual $i$ works in the local government sector and belongs to any of the post-reform cohorts, respectively. To account for differential trends in educational attainment/income, I also add interactions between years of schooling/income and cohort and years of schooling/income and local government. Differences in employment across the treatment and control group are captured by the term $\phi$. The identifying assumption of the effect of the reform, $\delta$, is that in the absence of the reform any trend in post-retirement health or 
utilization of health care should be the same for female local government employees and female private sector workers. This assumption is tested in Section 5.2.

\subsection{Data on retirements}

Individual demographics and labor market information is collected and maintained by Statistics Sweden. The Longitudinal Database on Education, Income and Employment (LOUISE) provides demographic and socioeconomic information. The data covers the entire Swedish population between 16 and 65 during the period 19872000, and individuals aged 16 to 74 between 2001 and 2010. The population of interest is local government workers whose NRA was increased from 63 to 65 in 2000. The main sample analyzed is composed of individuals born between 1935 and 1942. Those born in 1938 were the first ones to be affected by the new rules. The control group is made up of private sector workers in the same birth cohorts. The private sector workers faced a normal retirement age of 65 both before and after the local government pension reform.

Importantly, there is information in the data which allows me to distinguish these workers from other workers in the local government sector who had a NRA of 65 both before and after the reform. I use the Swedish Standard Classification of Occupations (SSYK-96) to identify workers in occupations who had a NRA of $63 .^{7}$ Individuals who are observed working in any of these occupations between ages 61 and 63 are included in the treatment group. I identify workers with a NRA of 65 in the same way. If an individual is observed working in both occupation categories, I use the most recent observation to determine the NRA. SSYK codes are available from 1996, which means that those born in 1935 is the oldest cohort for whom occupation status is known at age $61 .{ }^{8}$ I define someone as working in the private sector if she has not been employed in the public sector between ages 61 and 63. It is more difficult to determine private sector affiliation from the data. The data which contain the SSYK codes only contain a small representative sample of private sectors workers (around $23 \%$ ). In contrast, the universe of public sector workers is included in this data.

I make four restrictions to the sample of local government and private sector workers born between 1935 and 1942. First, because the affected worker categories in the local government sector were dominated by women, male workers are excluded from the analysis. In fact, only 3\% of these workers are men. Second, I restrict the analysis to individuals registered as employed for 12 full months in the year of their 61st birthday. This restriction ensures that I observe at least one SSYK code for each local government worker. In order for the SSYK code to be reported, the individual must be employed during the "reference month," which typically occurs at the end

\footnotetext{
${ }^{7}$ Standard för svensk yrkesklassificering (SSYK-96). SSYK-96 is based on the International Standard Classification of Occupations (ISCO-88).

${ }^{8}$ It is not possible to determine the NRA for all local government workers. The NRA cannot be determined for SSYK codes that map simultaneously to occupations with different NRAs. For example, pre-school teachers and after-school teachers have the same SSYK code (3310), but different NRAs. I therefore restrict the treatment group to workers in occupations where the SSYK code maps exclusively to a NRA of 63 .
} 
Table 1 Occupations in the treatment and control group

\begin{tabular}{|c|c|c|c|}
\hline \multicolumn{2}{|l|}{ Treatment group (local government) } & \multicolumn{2}{|l|}{ Control group (private sector) } \\
\hline Occupation & SSYK-96 & Occupation & SSYK-96 \\
\hline Personal care and related workers $(64 \%)$ & 513 & Salespersons $(31 \%)$ & 52 \\
\hline Restaurant service, housekeeping (15\%) & 512,913 & Plant and machine operators $(15 \%)$ & 8 \\
\hline $\begin{array}{l}\text { Nursing and midwifery professionals } \\
(13 \%)\end{array}$ & 223,323 & Clerks $(16 \%)$ & 4 \\
\hline Helpers and cleaners $(8 \%)$ & 912 & Manufacturing laborers (6\%) & 932 \\
\hline Physiotherapists $(<1 \%)$ & 5141 & Helpers and cleaners $(9 \%)$ & 912 \\
\hline \multirow[t]{5}{*}{ Hairdressers $(<1 \%)$} & 3226 & Craft and related trade workers $(6 \%)$ & 7 \\
\hline & & Restaurant service, housekeeping (7\%) & 512,913 \\
\hline & & Other associate professionals $(3 \%)$ & 34 \\
\hline & & Personal care and related workers $(3 \%)$ & 513 \\
\hline & & Professionals (2\%) & 2 \\
\hline
\end{tabular}

The first column reports the occupations in the local government sector that had a NRA of 63 before the reform (the treatment group). The third column reports the most common private sector occupations (the control group). The corresponding SSYK codes are listed in the second and fourth columns, respectively. The share of workers in each occupation are reported in parentheses. A worker is classified into an occupation if she is observed working in that occupation at any time between ages 61 and 63. The occupations are therefore not mutually exclusive. SSYK codes are only available for a representative sample of the private sector workers. The shares in this group are adjusted for sampling probabilities

of the year. In effect, this restriction implies that the first month in which individuals are allowed to retire is the month in which they turn 62. It does not, however, rule out part-time work. A part-time worker might well be registered as employed for 12 full months in a given year. At age 61, the sample of local government workers are approximately evenly split between working full-time, more than $75 \%$ but less than full-time, and less than $75 \%$, respectively. Third, I restrict the sample to individuals who have 5 years of consecutive employment prior to age 61 (at any work place). ${ }^{9}$ Finally, I also exclude individuals who are registered as self-employed at some point between ages 61 and 63. The final sample consists of 133,026 individuals of whom 57,415 are local government workers.

Table 1 reports the distribution of workers in the most numerous worker categories, and the corresponding SSYK codes, in the treatment and control group, respectively. The majority of the treatment group work within personal care. These include childcare workers, assistant nurses, home-based personal care assistants, and dental nurses. Other important worker categories in the treatment group are restaurant service workers, nursing professionals, and cleaners. The number of worker categories in the control group is larger since it includes both blue-collar and white-collar workers in the private sector. The most numerous worker categories in the control group

\footnotetext{
${ }^{9}$ An individual with an employer record in year $t$ is defined as employed.
} 
Table 2 Occupation characteristics in different countries

\begin{tabular}{|c|c|c|c|c|c|c|c|c|}
\hline \multirow[b]{2}{*}{ ISCO/SSYK } & \multicolumn{4}{|c|}{ Share in each occupation } & \multicolumn{4}{|c|}{ Share working full-time } \\
\hline & $\mathrm{DE}$ & EU-15 & SE & UK & $\mathrm{DE}$ & EU-15 & SE & UK \\
\hline 12 & 0.015 & 0.031 & 0.021 & 0.076 & 0.904 & 0.851 & 0.931 & 0.849 \\
\hline 21 & 0.013 & 0.011 & 0.017 & 0.008 & 0.771 & 0.841 & 0.867 & 0.864 \\
\hline 22 & 0.013 & 0.020 & 0.029 & 0.011 & 0.728 & 0.748 & 0.738 & 0.698 \\
\hline 23 & 0.043 & 0.065 & 0.066 & 0.063 & 0.564 & 0.751 & 0.796 & 0.678 \\
\hline 24 & 0.048 & 0.042 & 0.081 & 0.037 & 0.711 & 0.749 & 0.798 & 0.745 \\
\hline 31 & 0.023 & 0.015 & 0.016 & 0.011 & 0.762 & 0.794 & 0.849 & 0.762 \\
\hline 32 & 0.067 & 0.051 & 0.056 & 0.054 & 0.640 & 0.634 & 0.674 & 0.573 \\
\hline 33 & 0.029 & 0.016 & 0.039 & 0.005 & 0.633 & 0.674 & 0.702 & 0.725 \\
\hline 34 & 0.157 & 0.102 & 0.099 & 0.062 & 0.683 & 0.736 & 0.763 & 0.704 \\
\hline 41 & 0,170 & 0,163 & 0,104 & 0,190 & 0,601 & 0,686 & 0,683 & 0,622 \\
\hline 42 & 0,024 & 0.037 & 0.041 & 0.060 & 0.448 & 0.570 & 0.531 & 0.507 \\
\hline 51 & 0.118 & 0.137 & 0.237 & 0.170 & 0.564 & 0.603 & 0.489 & 0.452 \\
\hline 52 & 0.080 & 0.084 & 0.060 & 0.098 & 0.406 & 0.530 & 0.427 & 0.239 \\
\hline 61 & 0.014 & 0.020 & 0.013 & 0.002 & 0.700 & 0.773 & 0.635 & 0.504 \\
\hline 82 & 0.018 & 0.025 & 0.030 & 0.021 & 0.749 & 0.846 & 0.823 & 0.726 \\
\hline 91 & 0.067 & 0.093 & 0.060 & 0.080 & 0.162 & 0.402 & 0.431 & 0.255 \\
\hline
\end{tabular}

This table uses data from the 2003 wave of the European Union Labour Force Survey. The population is employed females in the age group 15+. Columns (2)-(5) show the share of these workers in different occupations, broken down by ISCO 2-digits and country/region (Germany, EU-15, Sweden, and the UK). Columns (6)-(9) report the fraction working full-time by occupation and country. The 2-digit versions of the treatment group occupations are marked in italics. I only report results for occupations that employ more than $1 \%$ of the population of interest in each country/region

are blue-collar jobs, including salespersons, plant and machine operators, manufacturing laborers, and craft workers. White-collar workers are foremost represented in the categories "other associate professionals" and "professionals" while "clerks" include both. Three of the treatment group occupations are found in the control group, too (personal care-related workers, restaurant service workers, and helpers and cleaners).

The treatment group occupations listed in Table 1 employ a significant share of working-age women in Sweden. The first four occupations all belong to the top 20 occupations that employ the most women, where personal care and related workers consistently rank as number one. ${ }^{10}$ These occupations are also important in other countries. Using data from the 2003 wave of the European Union Labour Force Survey, Table 2 reports the fraction of employed women aged 15 or above working in

\footnotetext{
${ }^{10}$ The Swedish Occupational Register with statistics (2003 and 2015).
} 
different occupations for a selected number of countries as well as EU-15. We see that these four occupations (at the 2-digit level) together employ around 30-40 percent of the female work force in each country/region. Table 2 also shows that the fraction of workers who work full-time within each occupation in Sweden is similar as in other countries. Both these things strengthen the generalizability of the results of this paper.

The retirement definition reflects the month in which an individual retires completely from the work force. This definition uses records of employment spells, which are obtained from the Register-Based Labor Market Statistics (RAMS). The information in RAMS is based on reports that all employers submit to the Swedish Tax Agency. For each employee, the employer must report how much wages and benefits have been paid out, how much taxes have been drawn and, most importantly, during which months the employee has been employed at the firm. This information allows me to infer in what month and year an individual exits the labor market. The decision to retire is equated with the month in which the individual's last employer reports the employment contract to be officially ended. The outcome variable in the first-stage analysis on the retirement effects of the reform is defined as the number of months an individual is registered as employed between ages 62 and 68. The upper limit of age 68 is chosen because it is the oldest age to which the youngest cohort can be tracked. ${ }^{11}$

I use two alternative measures of retirement. According to the first alternative definition, individuals who receive a positive amount of occupational pension income are classified as retired. The second definition is income-based. According to this definition, the individual retires the year before her annual earnings fall below 1 price base amount $(\approx$ USD 5900 in 2010). I use the record-based definition of retirement as my main definition of retirement because it much better captures the individual's actual exit from the labor force than the other two. Yearly fluctuations in income due to e.g. sickness or part-time work might cause individuals to cross the incomebased threshold of retirement at multiple occasions. Moreover, an individual who has started to collect pension income might still work. Occupational pension benefits can typically be withdrawn if the hours of work are reduced accordingly, and the new public pension puts no restriction on the amount of work individuals can work while collecting pension. One potential drawback of the record-based definition is that too much emphasis is put on economically unimportant spells of employment after the individual has quit her "real" job. However, as we will see, the reform caused a significant movement in the mass of retirements at the age at which we would expect to the see the largest effects, i.e., age 63. In addition, all three definitions produce similar effects on the retirement age.

\footnotetext{
${ }^{11}$ The employer records have been used in the Swedish context by Laun (2012). She studies the retirement effects of two age-targeted tax credits in 2007 using the number of remunerated months at age 65. Kreiner et al. (2014) use monthly payroll data on wages and salaries to study year-end tax planning in Denmark. A similar definition of retirement is also used in the Austrian context by Kuhn et al. (2010) and Manoli and Weber (2014).
} 


\subsection{Data on health care utilization and mortality}

I study mortality outcomes and two major types of health care utilization: hospitalizations and purchase of prescription drugs. Three register-based data sources are used for this purpose.

The analysis of drug prescriptions are based on data from the Prescription Drug Register, which contains information about all over-the-counter sales of prescribed medical drugs between 2005 and 2009. For each occasion when a prescription drug was bought, the data contains detailed information about the Anatomical Therapeutic Chemical (ATC) code of the drug, and the number of defined daily doses (DDDs) purchased over the entire period. The analysis of mortality is based on information from the Cause of Death Register. Causes of death are classified using the International Classification of Diseases (ICD). Hospitalizations are studied using information about inpatient care available in the National Patient Register. ${ }^{12}$ For each hospitalization event, the register has information about the arrival and discharge date, and diagnoses codes in ICD format. Inpatient records exist from 1964 to 2010, while the mortality data ends in 2011.

The analysis focuses on the extensive and the intensive margins of health care utilization. For the extensive margin, I define a set of binary outcome variables that equal 1 one if the individual is prescribed a non-zero quantity of drugs or is hospitalized for at least one night during a pre-specified time period. The intensive margin outcome variables for drug prescriptions are given by the product of the DDD per package and the number of prescribed packages, summed over the years 2005-2009 for each individual (expressed in thousands). Information on the number of days spent in hospital is used to construct intensive margin outcomes for inpatient care. The intensive margin adds important variation to the quantity of consumed health care, especially for individuals with previous records of health care utilization.

Because the different health registers cover different years, the pre-specified time period over which health outcomes are defined will vary across the type of health event. The mortality data ends in 2011 , which means that the maximum age up to which all cohorts can be tracked is 69. The outcome variable is thus set equal to 1 if the individual died before reaching this age. The hospitalization outcomes are based on an individual's hospital admissions between ages 65 and 68. Age 65 is chosen as the lower age limit because our primary interest lies in estimating the effects on health care utilization after the individual is retired. Finally, all drug outcomes are based on prescriptions made between 2005 and 2009.

A concern with using health care data is that the utilization of health care might reflect other factors than the need for health care. One such factor is ability to pay. In principle, receiving care must not be influenced by the ability to pay since most medical service expenses in Sweden are covered by taxes. There is, however, evidence

\footnotetext{
${ }^{12}$ Information on hospital admissions is provided by the National Board of Health and Welfare and covers all inpatient medical contacts at public hospitals from 1987 through 1996. From 1997 onward, the register also includes privately operated health care. Before 1997, virtually all medical care in Sweden was performed by public agents (Hallberg et al. 2015).
} 
that there exists pro-rich inequity in the utilization of health care (Van Doorslaer et al. 2000; Van Doorslaer et al. 2004). I diminish this risk by studying both the purchase of prescription drugs, where such inequity is likely to play a role, and outcomes severe enough to require hospital inpatient care. Another potential factor are differences in time availability between retirees and workers. Those who work longer as a result of the reform face a higher non-monetary cost of seeking health care. To make sure that the treatment and control group face similar time constraints, I focus on health care received after the age of 65 when most individuals are retired. ${ }^{13}$ Again, focusing on severe outcomes that either require inpatient care or lead to death should also play down the importance of help-seeking behavior associated with time availability.

\subsection{Descriptive statistics}

Table 3 shows descriptive statistics for pre- and post-reform cohorts for the treatment and control group, respectively.

The first row shows that post-reform cohorts in the treatment group retire about 5.4 months later than the pre-reform cohorts. The corresponding difference in the control group is very small, which yields a raw difference-in-differences estimate of 5.3 months. This is strong preliminary evidence that the reform had a positive impact on the retirement age. The second and third rows show that similar results are obtained for the two alternative measures of retirement. Since these definitions are measured at the yearly level, the raw difference-in-difference estimate in the second row of 0.56 reflects an increase in the claiming age of more than 6.5 months. The income-based definition of retirement reflects a smaller, yet sizable, effect of about 3 months. ${ }^{14}$

Table 3 shows that the two groups are similar in terms of several background characteristics, including marital status, the probability of having children (of any age) at home and immigrant status. The two groups also have similar pre-retirement health status. Sickness absence, measured as the number of years an individual has been absent from work for more than 14 consecutive days between ages 56 and 60, is only marginally higher in the treatment group, just like the probability of having been hospitalized during the same period. ${ }^{15}$ Differences apply mainly to education level and pre-retirement earnings. Local government workers have, on average, 0.50.6 years more of schooling and somewhat higher pre-retirement earnings than the private sector workers. The income distribution of the local government workers is, however, more compressed.

\footnotetext{
${ }^{13}$ The only case where I track health outcomes before the age of 65 is drug utilization for those born in 1941 and 1942 (the prescription data starts in 2005).

${ }^{14}$ Individuals are allowed to be retired from the age of 56 according to these definitions, which helps explain why the average retirement ages implied by these definitions are lower than the average retirement age implied by the main definition. The sample restrictions explained in Section 4 apply nonetheless.

${ }^{15}$ Specifically, our measure of sickness absence is the number of years the variable "sjukpp" in the LOUISE database takes on a non-zero positive value between ages 56 and 60. "Sjukpp" includes sickness benefits that are paid out by the Swedish Social Insurance Agency (Försäkringskassan). The Social Insurance Agency is responsible for paying out sickness benefits to individuals who have been sick for more than 14 consecutive days.
} 
Table 3 Descriptive statistics

\begin{tabular}{|c|c|c|c|c|c|c|c|}
\hline & \multicolumn{3}{|c|}{ Local government workers } & \multicolumn{3}{|c|}{ Private sector workers } & \multirow[b]{2}{*}{ Diff-in-diff } \\
\hline & Pre & Post & Diff & Pre & Post & Diff & \\
\hline \multicolumn{8}{|l|}{ Retirement } \\
\hline \multirow{2}{*}{$\begin{array}{l}\text { Employment, nr of } \\
\text { months btw } 62-68\end{array}$} & 36.19 & 41.56 & $5.37^{* * *}$ & 41.30 & 41.42 & 0.12 & $5.298^{* * *}$ \\
\hline & (24.09) & $(21.85)$ & {$[0.20]$} & $(23.61)$ & $(23.07)$ & {$[0.18]$} & {$[0.278]$} \\
\hline \multirow[t]{2}{*}{ Retirement age (claim age) } & 63.75 & 64.19 & $0.44^{* * *}$ & 63.83 & 63.71 & $-0.12^{* * *}$ & $0.560^{* * *}$ \\
\hline & $(1.98)$ & $(1.81)$ & {$[0.02]$} & $(2.48)$ & $(2.50)$ & {$[0.02]$} & {$[0.0259]$} \\
\hline \multirow{2}{*}{$\begin{array}{l}\text { Retirement age } \\
\text { (income-based) }\end{array}$} & 63.23 & 63.75 & $0.52^{* * *}$ & 62.95 & 63.23 & $0.28^{* * *}$ & $0.248^{* * *}$ \\
\hline & $(2.07)$ & $(2.51)$ & {$[0.02]$} & $(2.91)$ & (3.09) & {$[0.02]$} & {$[0.0305]$} \\
\hline \multicolumn{8}{|l|}{ Demographics } \\
\hline \multirow[t]{2}{*}{ Married } & 0.62 & 0.62 & -0.00 & 0.61 & 0.61 & -0.00 & 0.00214 \\
\hline & $(0.48)$ & $(0.49)$ & {$[0.00]$} & $(0.49)$ & $(0.49)$ & {$[0.00]$} & {$[0.00577]$} \\
\hline \multirow[t]{2}{*}{ Single } & 0.05 & 0.06 & $0.01^{* *}$ & 0.06 & 0.07 & $0.01^{* * *}$ & -0.00318 \\
\hline & $(0.23)$ & $(0.24)$ & {$[0.00]$} & $(0.24)$ & $(0.26)$ & {$[0.00]$} & [0.00280] \\
\hline \multirow[t]{2}{*}{ Divorced } & 0.17 & 0.19 & $0.02^{* * *}$ & 0.18 & 0.21 & $0.02^{* * *}$ & 0.000858 \\
\hline & $(0.37)$ & $(0.40)$ & {$[0.00]$} & $(0.39)$ & $(0.41)$ & {$[0.00]$} & [0.00459] \\
\hline \multirow[t]{2}{*}{ Widow } & 0.15 & 0.13 & $-0.03^{* * *}$ & 0.14 & 0.11 & $-0.03^{* * *}$ & 0.000187 \\
\hline & $(0.36)$ & $(0.33)$ & {$[0.00]$} & $(0.35)$ & $(0.32)$ & {$[0.00]$} & [0.00412] \\
\hline \multirow[t]{2}{*}{ Immigrant } & 0.10 & 0.09 & $-0.01^{* * *}$ & 0.11 & 0.11 & -0.00 & $-0.0105^{* * *}$ \\
\hline & $(0.30)$ & $(0.28)$ & {$[0.00]$} & $(0.32)$ & $(0.31)$ & {$[0.00]$} & [0.00362] \\
\hline \multirow[t]{2}{*}{ Children at home } & 0.13 & 0.11 & $-0.01^{* * *}$ & 0.11 & 0.11 & -0.00 & $-0.0104^{* * *}$ \\
\hline & $(0.33)$ & $(0.32)$ & {$[0.00]$} & $(0.31)$ & $(0.31)$ & {$[0.00]$} & [0.00382] \\
\hline \multirow[t]{2}{*}{ Years of schooling } & 10.30 & 10.69 & $0.40^{* * *}$ & 9.72 & 10.38 & $0.65^{* * *}$ & $-0.244^{* * *}$ \\
\hline & $(2.72)$ & (2.69) & {$[0.02]$} & (2.86) & $(2.97)$ & {$[0.02]$} & [0.0331] \\
\hline \multicolumn{8}{|l|}{ Income } \\
\hline \multirow[t]{2}{*}{ Log(average earnings 56-60) } & 11.92 & 12.04 & $0.12^{* * *}$ & 11.88 & 12.04 & $0.16^{* * *}$ & $-0.0421^{* * *}$ \\
\hline & $(0.34)$ & $(0.37)$ & {$[0.00]$} & $(0.68)$ & $(0.68)$ & {$[0.01]$} & {$[0.00615]$} \\
\hline \multirow[t]{2}{*}{ Log(std. dev. earnings 56-60) } & 9.26 & 9.64 & $0.38^{* * *}$ & 9.62 & 9.89 & $0.26^{* * *}$ & $0.122^{* * *}$ \\
\hline & $(0.84)$ & $(0.80)$ & {$[0.01]$} & $(0.99)$ & $(0.97)$ & {$[0.01]$} & {$[0.0106]$} \\
\hline \multicolumn{8}{|l|}{ Pre-retirement health } \\
\hline \multirow[t]{2}{*}{ Hospitalized ages 56-60 } & 0.25 & 0.24 & $-0.01^{* * *}$ & 0.25 & 0.24 & $-0.01^{* *}$ & -0.00510 \\
\hline & $(0.44)$ & $(0.43)$ & {$[0.00]$} & $(0.43)$ & $(0.43)$ & {$[0.00]$} & {$[0.00513]$} \\
\hline \multirow[t]{2}{*}{ Sickness benefits (years) } & 1.21 & 1.00 & $-0.21^{* * *}$ & 1.02 & 0.84 & $-0.18^{* * *}$ & $-0.0298^{* *}$ \\
\hline & $(1.27)$ & $(1.24)$ & {$[0.01]$} & $(1.24)$ & $(1.20)$ & {$[0.01]$} & {$[0.0145]$} \\
\hline \multicolumn{8}{|l|}{ Health outcomes } \\
\hline \multirow[t]{2}{*}{ Prescribed any drug } & 0.93 & 0.94 & $0.02^{* * *}$ & 0.93 & 0.95 & $0.02^{* * *}$ & $-0.00663^{* *}$ \\
\hline & $(0.26)$ & $(0.23)$ & [0.00] & $(0.26)$ & $(0.22)$ & {$[0.00]$} & [0.00297] \\
\hline \multirow{2}{*}{$\begin{array}{l}\mathrm{Nr} \text { of DDDs (in thousands), } \\
\text { all drugs }\end{array}$} & 52.33 & 45.52 & $-6.81^{* * *}$ & 50.73 & 44.08 & $-6.65^{* * *}$ & -0.279 \\
\hline & (64.94) & (61.97) & [0.56] & (65.10) & $(61.56)$ & [0.49] & [0.759] \\
\hline
\end{tabular}


Table 3 (continued)

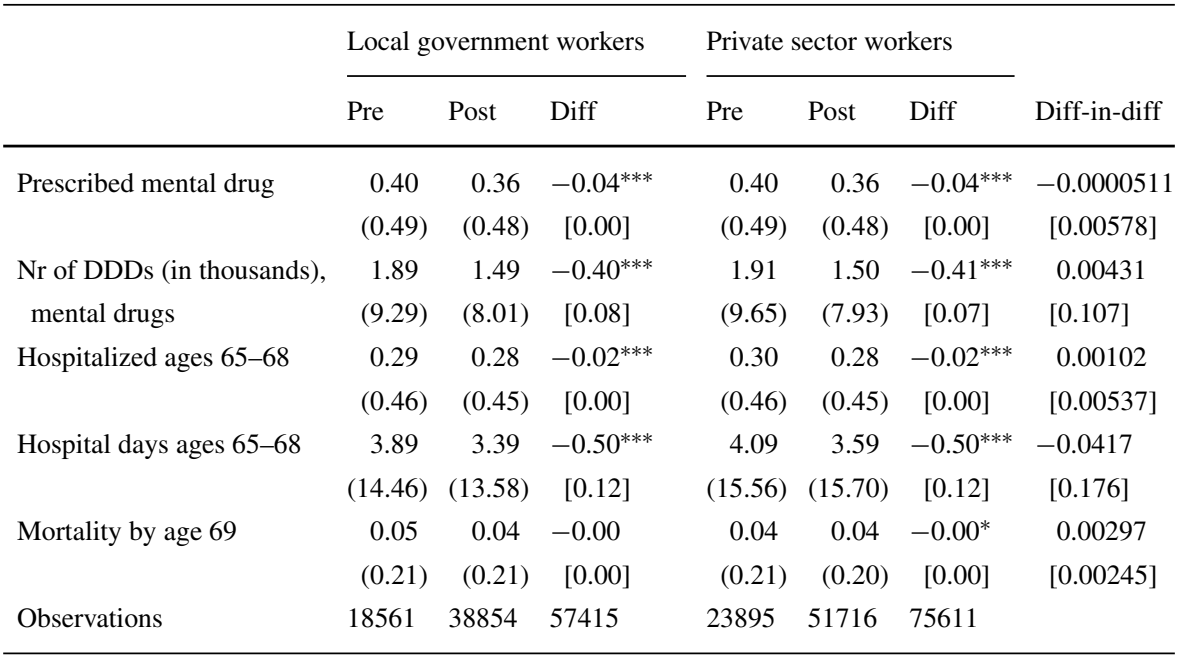

The sample includes female local government (treatment group) and private sector (control group) workers born between 1935 and 1942 who have 5 years of consecutive employment prior to age 61 (at any work place) and are registered as employed for 12 full months in the year of their 61st birthday. The sample of local government workers is restricted to workers in occupations whose NRA was increased from 63 to 65 in 2000. Earnings are in the 2010 price level. Retirement variables right-censored at age 68. Columns (1)(3) display statistics for the treatment group, while columns (4)-(6) consider the control group. Standard deviations in parentheses. Standard errors in squared parentheses. Pre-reform cohorts refer to those born before 1938. The difference-in-difference estimates in column (7) controls for sector and birth cohort

Turning to our health outcomes, we see that around $30 \%$ of the local government workers are hospitalized for at least one night between ages 65 and 68 . The private sector workers exhibit very similar hospitalization rates. The differences amount to less than $1 \%$ point. The two groups are also similar with respect to drug purchase. More than $90 \%$ of the individuals in the pre-reform cohorts are prescribed a non-zero quantity of drugs between 2005 and 2009. Around 40\% are prescribed mental drugs. Note, however, that the cross-cohort decline in drug purchase and hospital admissions is larger in the treatment group than in the control group (as indicated by the diff-indiff estimator in column (7)). The opposite pattern is seen for our two measures of mortality, i.e., the probability of being dead by the age of 69 . In sum, it is difficult to draw any conclusions about the existence of an effect of the reform on mortality and health care utilization based on these raw difference-in-difference estimates.

\section{Analysis}

In this section, I first show the impact of the reform on the retirement age. The parallel trends assumption is tested in Section 5.2. The main results for health care utilization and mortality are presented in Section 5.4 and Appendix A.3 analyzes heterogeneous treatment effects. 


\subsection{The impact of the reform on retirement}

We know from the descriptive statistics in Section 4.4 that post-reform cohorts in the treatment group retire more than 5.3 months later than the corresponding birth cohorts in the control group. This section aims at quantifying the impact of the reform on retirement in more detail.

The retirement effects of the reform are perhaps best illustrated in a histogram. Figure 1 shows the retirement distribution for pre- and post-reform cohorts in the treatment group. Most evident in the left-most panel is the spike of retirements around age 63 . The spike around 65 is also pronounced, which means that many workers continue to work past the age at which they become entitled to full pension benefits. The two oldest post-reform cohorts, i.e., those born in 1938 and 1939, seem to retire later than the pre-reform cohorts, but the spike around 63 is only marginally smaller. Remarkably, it almost vanishes for the 1940-1942 cohorts. These graphs provide clear evidence that the reform increased the actual retirement age.

I proceed by estimating the difference-in-difference Eq. 1 with the number of months employed between age 62 and 68 on the left-hand side:

$$
R_{i, j, s}=\alpha+\psi\left(L G_{s} \times C H_{j \in[1938,1942]}\right)+\phi L G_{s}+\lambda_{j}+\mathbf{X}_{i, j, s} \theta+u_{i, j, s}
$$
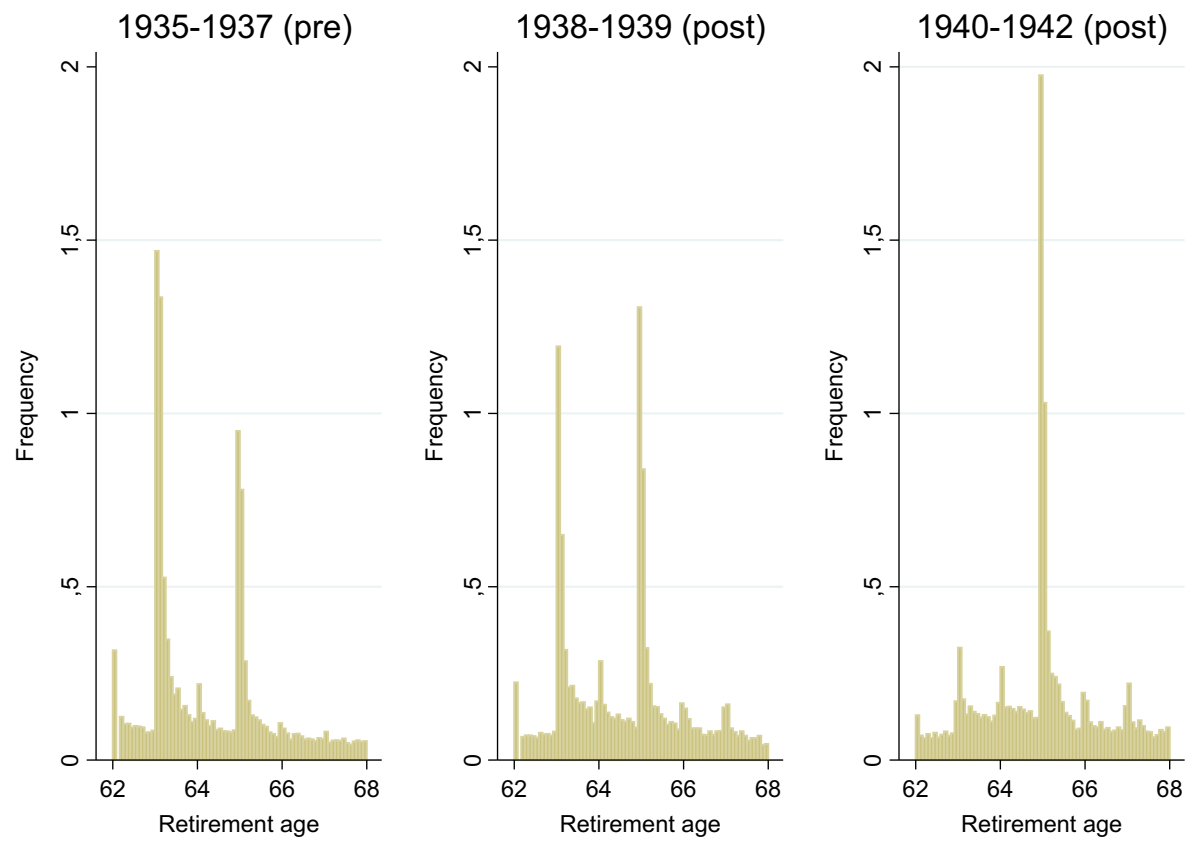

Fig. 1 Retirement distribution for local government workers (by cohort). Histogram of retirements in the treatment group. The decision to retire is equated with the month in which the individual's last employer reports the employment contract to be officially ended. See Table 3 for more information on the sample of analysis 
The common treatment effect, $\hat{\psi}$, is presented in column (1) of Table 4. Column (2) presents the results when we allow for heterogeneous effects across birth cohorts, i.e.:

$$
R_{i, j, s}=\alpha+\sum_{j} \psi_{j}\left(L G_{s} \times C H_{j \in[1938,1942]}\right)+\phi L G_{s}+\lambda_{j}+\mathbf{X}_{i, j, s} \theta+e_{i, j, s}
$$

The common treatment effect amounts to 4.5 months and column (2) shows that this effect is largely driven by the youngest cohorts. For example, those born in 1942 retire more than 6.2 months later than the pre-reform cohorts as compared to 1.4 months for those born in 1939.

Table 4 The impact of the reform on retirement

(1)

$4.474^{* * *}$

(0.274)

Cohort 1938 * LG

Cohort 1939 * LG

Cohort $1940 *$ LG

Cohort 1941 * LG

Cohort $1942 *$ LG

Pre-reform cohorts

Cohort $1936 *$ LG

Cohort 1935 * LG

Observations

133026

40.708

Mean dep. var 265.869

$F$ statistic
(2)

(3)

\section{$2.695^{* * *}$ \\ (0.424)}

$1.893^{* * *}$

(0.418)

$5.691^{* * *}$

(0.397)

$5.371^{* * *}$

(0.395)

$6.217^{* * *}$

(0.379)

$2.159^{* * *}$

$1.358^{* * *}$

$4.836^{* * *}$

$5.684^{* * *}$

ref.

$-0.603$

$-1.057^{*}$

133026

40.708

45.792

Column (1) shows first-stage estimates from Eq. 2 and columns (2) and (3) from Eq. 3. Column (3) adds two pre-reform interaction terms between cohort $j=1935,1936$ and the local government dummy to the specification in column (2). Robust standard errors in parentheses. Dependent variable: number of months employed from age 62 to 68. Estimated using OLS. Dependent variable right-censored at 72 (age 68). All regressions include cohort-fixed effects, regional dummies, and dummies for month of birth. Additional control variables are the $\log$ of the average of yearly earnings between ages 56 and 60 , the $\log$ of the standard deviation of yearly earnings between ages 56 and 60, number of years of schooling, dummies for immigrant status and having children at home, the number of years with more than 14 consecutive days of sick leave between ages 56 and 60, and interactions between schooling years/income and cohort and schooling years/income and local government. $* * *, * * *$ denote statistical significance at the 1,5 , and $10 \%$ levels, respectively. See Table 3 for more information on the sample of analysis 
How can we be sure that this movement in the retirement mass is not only the result of a general trend towards longer working lives? Figure 2 shows retirement distributions for the control group. Except for a slight decrease in the mass of retirements at ages 62 and 63, little seems to happen across these birth cohorts. I also estimate pre-reform trends for the retirement age in a similar fashion as for health in the previous section. Column (3) of Table 4 reports the estimation results after adding two interaction terms between pre-reform cohort $j=1935,1936$ and the local government dummy to the specification in column (2). The estimated coefficients imply that local government workers born in 1935 and 1936 retire 0.5 and 1.1 months earlier than those born in 1937, respectively, accounting for the corresponding change in the control group. The coefficient for the 1935 cohort is significant at the $10 \%$ level while the coefficient for the 1936 cohort is insignificant. These results support the interpretation that the first-stage effects are the result of the reform itself rather than a differential underlying trend in retirement age between the treatment and control group.

There are several plausible explanations for the between-cohort differences in labor supply response observed in columns (2) and (3). First, if norms adjust slowly in response to a change in the NRA, we should expect the labor supply adjustments to increase over time. In this specific case, though, the importance of norms should not be exaggerated. Sixty-five was already the NRA in all other major occupational
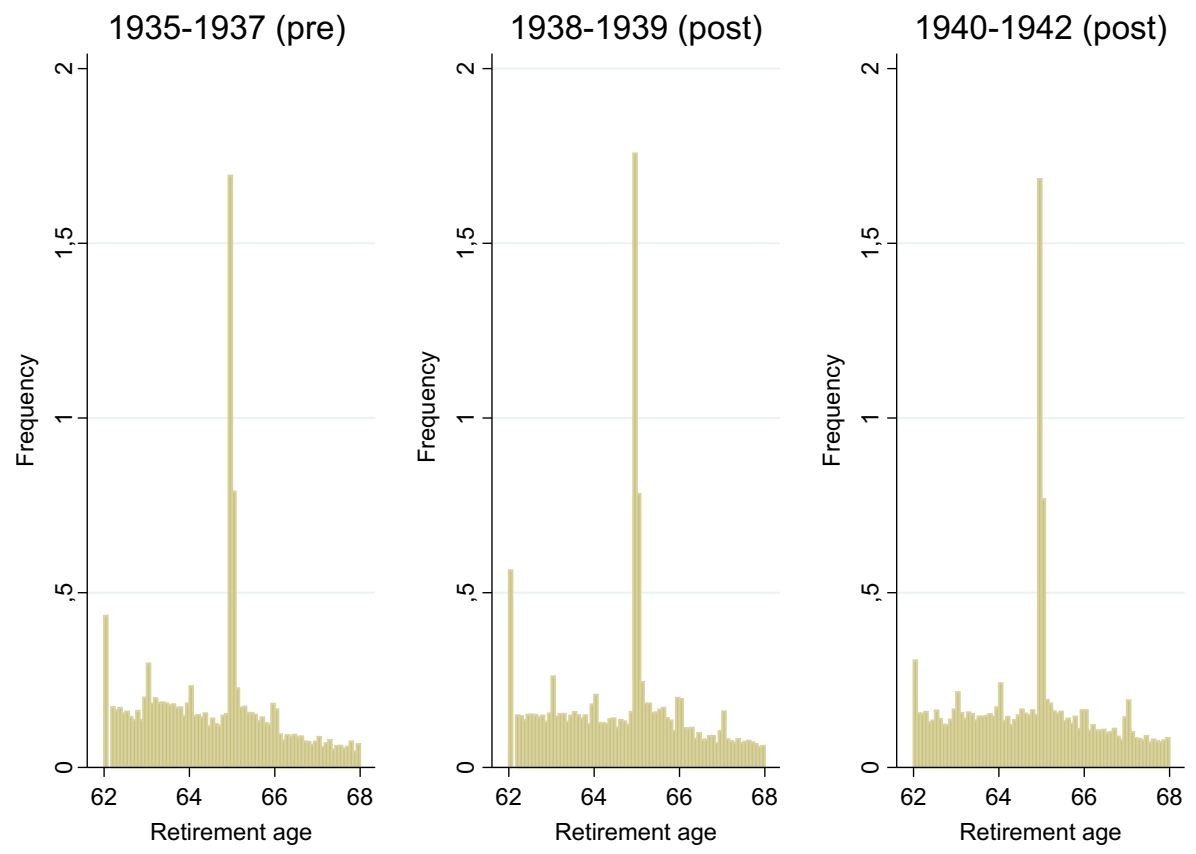

Fig. 2 Retirement distribution for private sector workers (by cohort). Histogram of retirements in the control group. The decision to retire is equated with the month in which the individual's last employer reports the employment contract to be officially ended. See Table 3 for more information on the sample of analysis 
pension plans as well as in the public pension system. Second, an immediate adjustment in response to changes in incentives could be prevented by adjustment costs or frictions (Gelber et al. 2013). Although the financial incentives to retire before 65 changed very quickly with the reform, there might be large non-financial costs of changing the retirement plans on short notice. Such costs should be higher for older cohorts that received news about the new rules just before they reached their intended retirement age.

Table 13 shows the first-stage effects for the alternative retirement definitions. Columns (1) and (2) show that the reform also had a significant impact on claiming behavior. The common treatment effect of 0.49 translates into an increase in the actual claiming age of 5.9 months. The income-based definition of retirement yields an estimate of 0.37 years or 4.4 months. Again, we see that the effect is driven by the youngest cohorts. Thus, these results verify that the reform effect on employment is robust to various definitions of retirement.

Can we say something about the characteristics of those who postpone their retirement date as a result of the reform (commonly referred to as the "compliers")? Following Angrist and Pischke (2008), Table 5 reports the relative likelihood a complier has the characteristic indicated in the column heading. We see that compliers are relatively similar to other individuals in terms of marital status, pre-retirement income level and work amount (part-time vs. full-time). Instead, compliers are more likely to be in worse health (as measured by sickness absence and hospitalizations prior to the age of 60). They are also more likely to have a retired spouse than other married individuals, which provides evidence in favor of the complementarity-inleisure hypothesis. Finally, compliers are less likely to have finished only elementary school.

\subsection{Identifying assumption}

The parallel trends assumption implies that the outcome variable evolved in the same way in the treated group as in the control group in absence of the reform. Figure 3 plots series of average outcomes for the treatment and control group before and after the reform for the main health measures. The two top panels show that the probability of being prescribed a non-zero quantity of prescription drugs and the total purchase of drugs evolved similarly for pre-reform cohorts in the two groups. The lower panels show that post-retirement hospitalization and mortality rates also seem to satisfy the

Table 5 Complier characteristics ratios

\begin{tabular}{lllllll}
\hline Elem. school & Married & Non-ret. spouse & Inc. < med. & Sick leave & Hospital visit & Part-time \\
\hline 0.688 & 0.999 & 1.255 & 0.874 & 1.259 & 1.190 & 0.844 \\
\hline
\end{tabular}

This table reports an analysis of complier characteristics. Each column entry gives the relative likelihood that compliers have the characteristics indicated in the heading, i.e., the ratio of the first stage for individuals with the respective characteristic to the overall first stage 

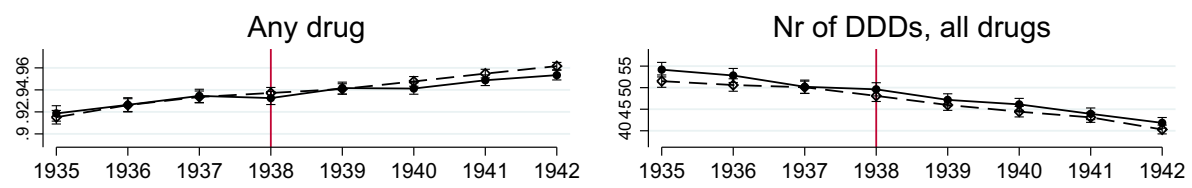

Any mental drug

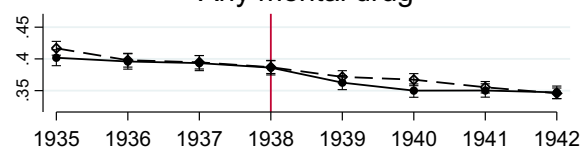

$\mathrm{Nr}$ of DDDs, mental drugs

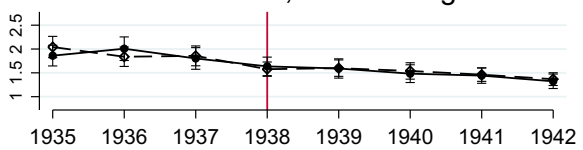

Hospitalized (yes/no) ages 65-68

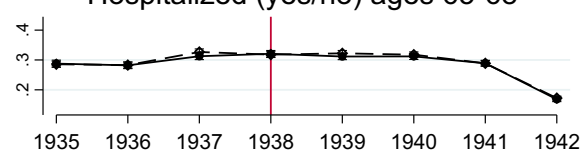

Hospital days

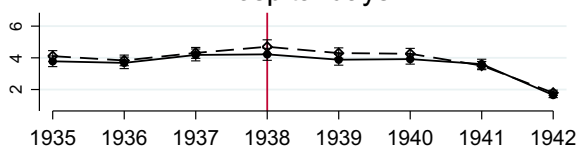

Mortality by age 69

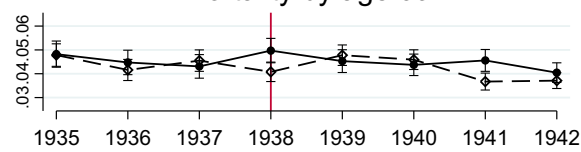

Fig. 3 Comparing the treatment and control group. This figure plots the means and the corresponding $95 \%$ confidence intervals of the main health outcomes by cohort and treatment status. Solid and dashed lines refer to the treatment and control group, respectively. The confidence interval is obtained by regressing each health outcome on a constant, separately by cohort and treatment status. Number of DDDs are expressed in thousands

parallel trends assumption. It is also reassuring that the levels are similar across the two groups.

We can test the parallel trends assumption more formally by estimating prereform trends in the difference-in-difference framework. Specifically, I extend Eq. 1 by adding two interaction terms between the local government dummy and cohorts $j=1935,1936$. For the parallel trends assumption to hold, the estimated $\delta_{j}$ coefficients for these two cohorts should be close to zero and insignificant. Table 6 reports the estimation results for the health outcomes shown in Fig. 3. There are 14 estimates in total and only one of them is significant (at the $10 \%$ level). This supports the assumption that health developed similarly in the treatment and control group prior to the reform.

As mentioned in Section 3.2, the 1938 and 1939 cohorts could avoid the new rules by retiring prior to the reform. Such anticipatory behavior might be a problem to the identification strategy if it changed the composition of the treatment and control group in a way that is related to health. The preferred way to test for this would be to apply a similar DD framework as in the main analysis and look specifically at retirement behavior at ages 60-61 for the affected cohorts. However, a simultaneous reform in the public pension system makes such an analysis difficult. In 1998, the minimum claiming age in the public pension system was raised from 60 to 61 (Palme and Svensson 2004). As a result, individuals born in 1938 had to wait an 
Table 6 Estimation of parallel trends

\begin{tabular}{|c|c|c|c|c|c|c|c|}
\hline & \multicolumn{2}{|l|}{ All drugs } & \multicolumn{2}{|c|}{ Mental drugs } & \multicolumn{2}{|c|}{ Inpatient care ages $65-68$} & \multirow{2}{*}{$\begin{array}{l}\text { Mortality } \\
\text { (7) }\end{array}$} \\
\hline & (1) & (2) & (3) & (4) & (5) & (6) & \\
\hline & Any & Dose & Any & Dose & Any visit & Days & By age 69 \\
\hline Cohort $1936 *$ LG & $\begin{array}{r}-0.00110 \\
(0.00607)\end{array}$ & $\begin{array}{c}1.972 \\
(1.533)\end{array}$ & $\begin{array}{r}-0.00404 \\
(0.0115)\end{array}$ & $\begin{array}{c}0.194 \\
(0.226)\end{array}$ & $\begin{array}{c}0.0136 \\
(0.0109)\end{array}$ & $\begin{array}{l}0.00661 \\
(0.365)\end{array}$ & $\begin{array}{c}0.00645 \\
(0.00488)\end{array}$ \\
\hline Cohort $1935 *$ LG & $\begin{array}{r}-0.000251 \\
(0.00632)\end{array}$ & $\begin{array}{c}1.791 \\
(1.555)\end{array}$ & $\begin{array}{r}-0.0200^{*} \\
(0.0117)\end{array}$ & $\begin{array}{r}-0.179 \\
(0.228)\end{array}$ & $\begin{array}{c}0.0114 \\
(0.0110)\end{array}$ & $\begin{array}{r}-0.241 \\
(0.362)\end{array}$ & $\begin{array}{c}0.00428 \\
(0.00505)\end{array}$ \\
\hline Observations & 42456 & 42456 & 42456 & 42456 & 42456 & 42456 & 42456 \\
\hline Mean dep. var. & 0.940 & 46.849 & 0.374 & 1.624 & 0.283 & 3.662 & 0.044 \\
\hline
\end{tabular}

Note: This table shows estimates from estimating Eq. 1 after adding two pre-reform interaction terms between cohort $j=1935,1936$ and the local government dummy. See Tables 3 and 4 for more information on the sample of analysis and controls. Robust standard errors in parentheses. ***, **, * denote statistical significance at the 1,5 , and $10 \%$ level, respectively

additional year before they could claim public pension benefits. In contrast to private sector workers who were directly exposed to the new minimum claiming age, local government workers were unaffected by this reform as long as they retired under the pre-reform rules. Thus, we would not know to what extent a DD estimator would reflect anticipatory behavior among local government workers on the one hand, and later retirement among private sector workers on the other. Instead, I do two things to deal with this issue. First, by conditioning on being employed for 12 full months in the year of their 61st birthday, I exclude most individuals who potentially retire in anticipation of the reform. Second, I test whether the results are robust to excluding the 1938 and 1939 cohorts. These robustness tests, along with several others, are provided in the Appendix.

\subsection{Income effects}

One important aspect of estimating the health effects of reforms that promote later retirement is that these effects may operate through changes in lifetime income. ${ }^{16}$ To illustrate the effect of the reform on lifetime income, I replace the dependent variable in Eq. 1 with $\log$ disposable income at age $a$ and estimate it for ages $a=61, \ldots, 69$. The difference-in-difference estimates from these regressions are shown in Fig. 4. There is a positive and significant effect on disposable income of about $2-5 \%$ at ages 63-66, which corresponds to an annual increase in disposable income of SEK 3,500 to SEK 8,500. This reflects the increased labor supply at ages 63-64 and the corresponding difference between labor earnings and pension benefits. From age 67,

\footnotetext{
${ }^{16}$ There is a large literature on the health effects of income loss due to unemployment (e.g. Black et al. 2012; Eliason and Storrie 2009a). The direction of the income effect on health is not clear, however. Jensen and Richter (2004) show that an unexpected pension benefit reduction among Russian pensioners increased mortality, whereas Ruhm (2000) show that fatalities decline during recessions.
} 


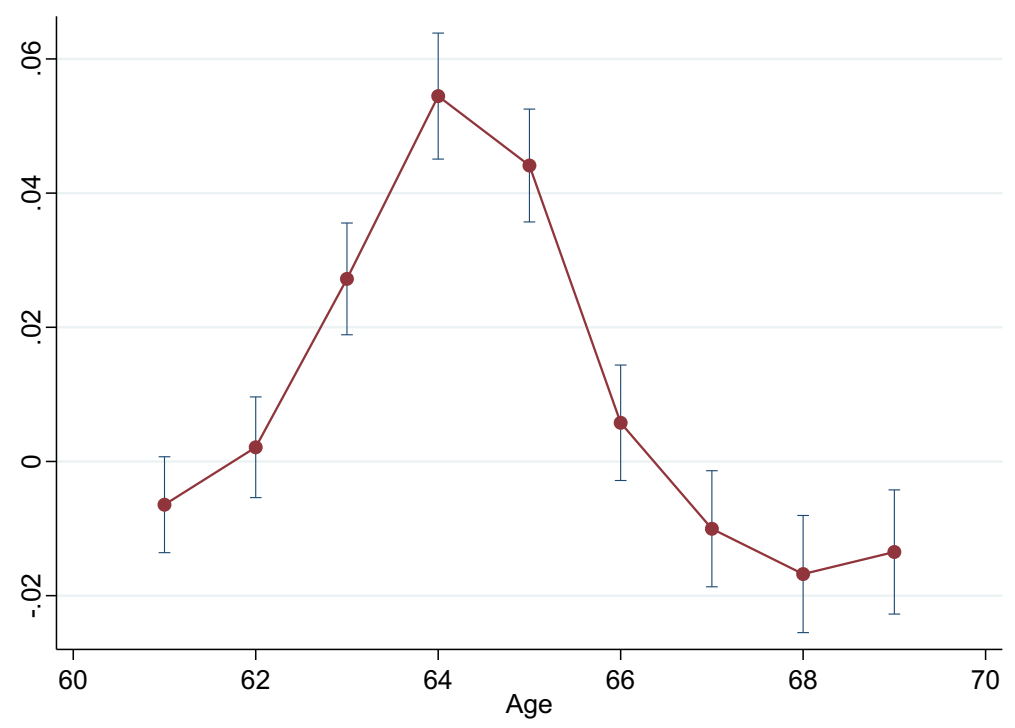

Fig. 4 The effect on disposable income of the reform. This figure plots the coefficient estimates from the interaction term in a difference-in-difference specification of the effect of the reform on log disposable income at age $a$

the effect is negative and barely statistically different from zero. Remember that the transition rule explained in Section 3.2 implied that the pension wealth at age 65 was more or less unchanged for the first post-reform cohorts. The conclusion from these results is that the income effects should be rather small and that potential health effects are more likely to operate through other channels.

\subsection{The impact of the reform on health}

The results from estimating Eq. 1 are presented in Table 7. The reported coefficients measure the reform effect on each of the health outcomes given in the column headings.

I find no effect on the utilization of prescription drugs. The extensive margin outcomes in columns (1) and (3), i.e., the probability of being prescribed a non-zero quantity of any drug or any mental drug, respectively, are insignificant and close to zero. The same is true for the intensive margin results in columns (2) and (4). In relative terms, the effect sizes range between -0.5 and $1.55 \%$. The estimates for inpatient care and mortality are also insignificant and close to zero. The coefficient in column (7) implies that the reform increased the probability of dying before the age of 69 by $0.16 \%$ points, which translates into a small relative effect of $3.68 \%$.

Even if all estimates are insignificant, we cannot rule out that later retirement has an impact on health. A key issue in ruling out effect sizes of important magnitude is the precision of the estimates. The extensive margin drug and hospital outcomes are estimated with high precision. The relative effects associated with the $95 \%$ confidence intervals consistently range within a few percentage points around zero. The 
Table 7 Effects on prescription drugs, inpatient care, and mortality

\begin{tabular}{|c|c|c|c|c|c|c|c|}
\hline & \multicolumn{2}{|l|}{ All drugs } & \multicolumn{2}{|c|}{ Mental drugs } & \multicolumn{2}{|c|}{ Inpatient care ages $65-68$} & \multirow{3}{*}{$\begin{array}{l}\text { Mortality } \\
\text { (7) } \\
\text { By age 6s }\end{array}$} \\
\hline & (1) & (2) & (3) & (4) & (5) & (6) & \\
\hline & Any & Dose & Any & Dose & Any visit & Days & \\
\hline $\mathrm{CH} * \mathrm{LG}$ & $\begin{array}{r}-0.00473 \\
(0.00300)\end{array}$ & $\begin{array}{r}-0.286 \\
(0.766)\end{array}$ & $\begin{array}{c}0.00451 \\
(0.00578)\end{array}$ & $\begin{array}{c}0.0252 \\
(0.107)\end{array}$ & $\begin{array}{c}0.000940 \\
(0.00544)\end{array}$ & $\begin{array}{r}-0.121 \\
(0.179)\end{array}$ & $\begin{array}{c}0.00162 \\
(0.00248)\end{array}$ \\
\hline Observations & 133026 & 133026 & 133026 & 133026 & 133026 & 133026 & 133026 \\
\hline Mean dep. var. & 0.940 & 46.849 & 0.374 & 1.624 & 0.283 & 3.662 & 0.044 \\
\hline
\end{tabular}

This table presents intention-to-treat estimates of the reform (1). Estimation is performed using OLS. See Tables 3 and 4 for more information on the sample of analysis and controls. Robust standard errors in parentheses. $* * *, * *, *$ denote statistical significance at the 1,5 , and $10 \%$ levels, respectively

intensive margin results have lower precision. For example, the $95 \%$ confidence interval of the estimate for the number of hospital days in column (6) corresponds to relative effects of -12.9 to $6.3 \%$. For mortality by age 69 , the corresponding interval ranges from -7.4 to $14.8 \%$. Given that only $4.4 \%$ of the individuals in the sample are deceased by age 69 , it comes as no surprise that the standard error of the mortality estimate is quite large. I come back to the issue of precision in Section 9.

Next, I explored in detail the diagnoses codes to see whether the small effects on health care utilization and mortality mask any heterogeneous effects with respect to the hospitalization cause. I examine five medical causes based on their known relationship with retirement in the previous medical and health-economic literature. These include heart disease, cerebrovascular disease (stroke), diseases of the musculoskeletal system, lifestyle diseases (diabetes and alcohol/tobacco related diseases) and mental health. Diseases of the circulatory system (e.g. hypertension, myocardial ischemia and stroke) can often be related to stress and are often caused by correctable health-related behavior, such as an unhealthy diet, lack of exercise, being overweight, and smoking. I therefore complement this analysis by examining health events that are directly related to alcohol and tobacco consumption as well as type 2 diabetes. ${ }^{17}$ Diseases of the musculoskeletal system are included to investigate whether postponing retirement has an effect on physical body functions. The mental health category includes drugs that treat psychosis, depression, anxiety and sleeping disorders.

\footnotetext{
${ }^{17}$ Previous studies have produced mixed results. Retirement has been shown to increase the risk of both heart disease (Behncke 2012), stroke (Moon et al. 2012), obesity (Godard 2016), and diabetes (Dave et al. 2008). In contrast, Bloemen et al. (2013) and Hallberg et al. (2015) report that retirement reduces the risk of heart-related mortality, and Insler (2014) shows that the observed beneficial influence of retirement on health could be explained by a reduction in smoking.
} 
Table 8 Cause-specific health indexes

\begin{tabular}{lccccc}
\hline & Heart & Stroke & Musculoskeletal & Lifestyle & Mental health \\
\hline CH * LG & -0.00343 & $0107 *$ & -0.000130 & 0.00376 & 0.00318 \\
& $(0.00529)$ & $(0.00638)$ & $(0.00555)$ & $(0.00537)$ & $(0.00502)$ \\
Observations & 133026 & 133026 & 133026 & 133026 & 133026 \\
Mean dep. var. & 0.034 & 0.036 & 0.055 & 0.031 & 0.057 \\
\hline
\end{tabular}

This table presents intention-to-treat estimates of the reform on five cause-specific health indexes. I combine information on the type of drug, the medical cause for hospitalization, and the cause of death to create each health index. "Lifestyle" refers to alcohol- and tobacco-related health events and diabetes. See Table 11 for the aggregation of the ICD and ATC codes. A better health outcome is represented by a higher index value. The Estimation is performed using OLS. See Tables 3 and 4 for more information on the sample of analysis and controls. Robust standard errors in parentheses. $* * *, * *$, denote statistical significance at the 1,5 , and $10 \%$ levels, respectively

Mortalities and hospital admissions are readily classified into each of these causes using the ICD codes. The ATC codes are then used to classify prescription drugs into categories that closely resemble the ICD classification. The aggregation of the ICD and ATC codes are described in Table $11 .^{18}$

To mitigate problems with multiple hypothesis testing, I combine information on cause-specific mortalities and health care utilization to create health indexes for each of these medical categories. First, I invert each outcome so that a higher value represents a better outcome. Then, I standardize each modified outcome by subtracting the control group mean and dividing by the control group standard deviation. Finally, I take an equally weighted average of the standardized outcomes. Table 8 presents the estimation results.

Again, the overall result is that the reform had no impact on post-retirement health. The only statistically significant coefficient is the coefficient related to cerebrovascular disease (significant at the $10 \%$ level). Because a higher index value indicates a better outcome, the positive estimate implies that the reform reduced health problems related to cerebrovascular disease. This results suggests that continued work at older ages might provide individuals with better opportunities to preserve a healthy lifestyle than retirement since many of the risk factors for cerebrovascular disease are related to lifestyle. However, this result should be interpreted with caution because there is no direct effect on diabetes and alcohol/tobacco related diseases.

\subsection{The effects of retirement on health}

Up until now, I have focused on the effects of the reform on health (i.e., the intentionto-treat effect). However, as discussed in Section 2, previous studies have focused

\footnotetext{
${ }^{18}$ Following Cesarini et al. (2015), I merge ischemic heart disease and hypertension into a single category ("Heart") because many drugs are used to treat both these illnesses. Second, I limit the set of drugs used to treat musculoskeletal diseases (ATC code "M") to analgesics (painkillers). Third, I do not try to classify drugs into "Alcohol and Tobacco" due to the complexity of the prescription data.
} 
on the effects of retirement on health. To better relate to these studies, I estimate the health effects of postponing retirement in an Instrumental Variable framework, where the endogenous employment variable is instrumented by several interaction terms between being born in 1938 or later and working in the local government sector. This means that I estimate the causal effect for those individuals who postpone retirement due to the reform, i.e., the compliers. Assuming heterogeneous effects of postponing retirement on health, the 2SLS estimator estimates the local average treatment effect (LATE) instead of the average treatment effect (ATE). The coefficient of interest reflects the reform effect on the number of months employed before exiting the labor market, comparing local government workers born in 1938 or later to private sector workers in the same birth cohorts. The 2SLS estimates for the main outcomes and the cause-specific health indexes are presented in Tables 9 and 10, respectively.

The OLS estimates reflect the negative correlation that is typically observed between retirement age and health (those who retire early tend to be in worse health), but cannot be used to make any causal claims about the effect on retirement on health due to non-random selection into retirement. When health selection into retirement is controlled for, the negative relationship between retirement age and health disappears. All 2SLS estimates, but one ("any drug"), are statistically insignificant. These results are thus largely in line with the intention-to-treat effects.

As discussed previously, a key issue in ruling out effect sizes of important magnitude is the precision of the estimates. The 2SLS estimation allows me to compare the precision of the mortality estimates to those of two previous studies. The most comparable study is Hernaes et al. (2013) who investigate the mortality effects of lowering the early retirement age for a group of Norwegian workers using a similar difference-in-difference strategy as in this paper. They find that a 1-year increase in the actual retirement age results in a $0.2 \%$ point increase in mortality by age 70 (insignificant), which is somewhat smaller than what I find for mortality by age 69 $\left(0.34 \%\right.$ points). ${ }^{19}$ The effects are, however, estimated with similar precision. Hernaes et al. (2013) report a 95\% confidence interval that ranges from $-0.78-1.18 \%$ points compared to -0.73 to 1.41 in this study. In another related study, Kuhn et al. (2010) find that the introduction of more generous early retirement rules for Austrian blue-collar workers had a significant effect on mortality among male workers, but no effect among female workers. For women, Kuhn et al. (2010) report that one additional year spent in early retirement results in a $0.02 \%$ point increase in mortality at age 67 . The effect is thus very close to zero, but the confidence interval ranges from -1.84 to $1.88 \%$ points. $^{20}$

\footnotetext{
${ }^{19}$ Multiply the 2SLS estimate for mortality in column (7) of Table 9 by 12 to express in number of years: $0.00028 \times 12=0.0034$

${ }^{20}$ I conducted a number of sensitivity analyses of the main findings. These are described and presented in the Appendix A.2. The Appendix also has a section dedicated to the analysis of whether the reform had differential health effects on different types of workers. I analyze heterogeneous effects with respect to preretirement income, initial health, work amount (part-time vs. full-time), and marital status. The analysis confirms the overall zero result on health with a couple of interesting exceptions. First, individuals with low income are more likely to suffer from heart-related disease and stroke compared to individuals with high income. Low-income individuals, on the other hand, fare significantly better in terms of musculoskeletal disease. Finally, individuals with records of sickness absence prior tor retirement are less likely to be prescribed mental health drugs than individuals with no such records.
} 


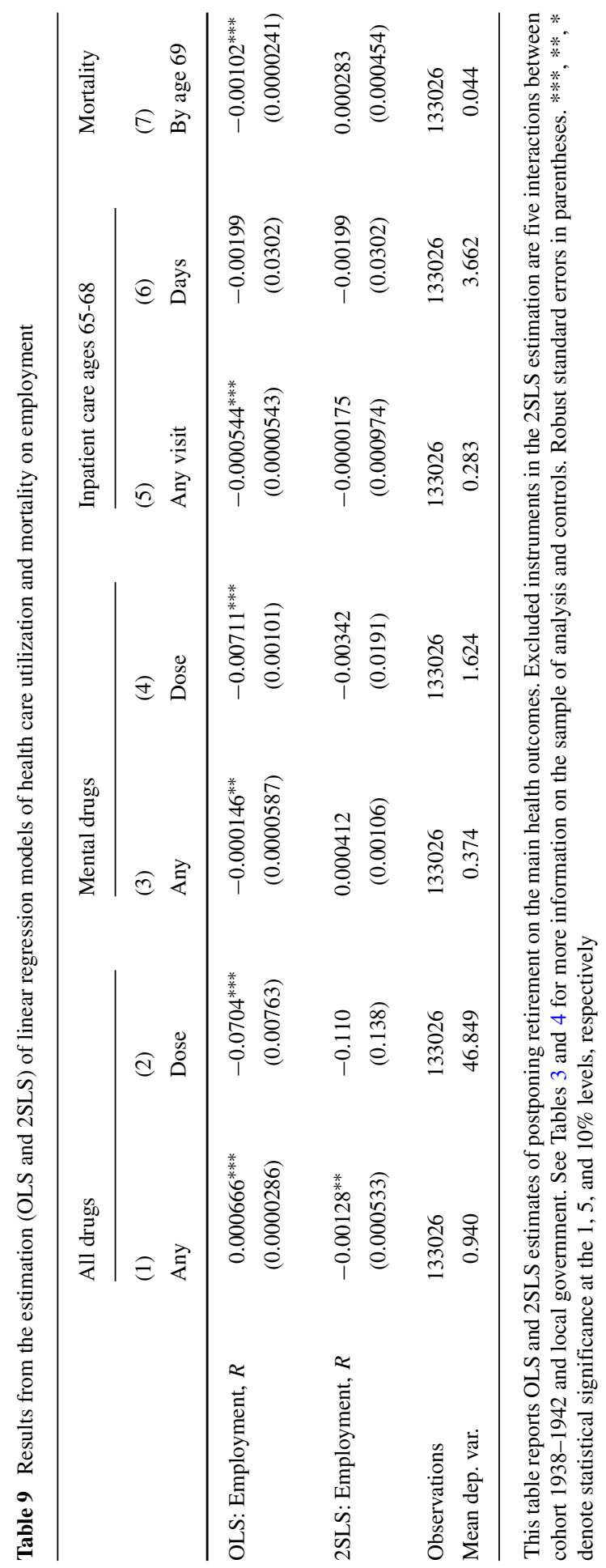


Table 10 Results from the estimation (OLS and 2SLS) of linear regression models of cause-specific health care utilization and mortality on employment

\begin{tabular}{lccccc}
\hline & Heart & Stroke & Musculoskeletal & Lifestyle & Mental health \\
\hline OLS: Employment, $R$ & $\begin{array}{c}0.000869^{* * *} \\
(0.0000527)\end{array}$ & $\begin{array}{c}0.000892^{* * *} \\
(0.0000603)\end{array}$ & $\begin{array}{c}0.000125^{* *} \\
(0.0000561)\end{array}$ & $\begin{array}{c}0.00107^{* * *} \\
(0.0000528)\end{array}$ & $\begin{array}{c}0.000460^{* * *} \\
(0.0000496)\end{array}$ \\
& & & & & \\
2SLS: Employment, $R$ & -0.000776 & 0.00163 & -0.000721 & -0.0000939 & 0.000844 \\
& $(0.000958)$ & $(0.00112)$ & $(0.00101)$ & $(0.000966)$ & $(0.000906)$ \\
$N$ & 133026 & 133026 & 133026 & 133026 & 133026 \\
Mean dep. var. & 0.034 & 0.036 & 0.055 & 0.031 & 0.057 \\
\hline
\end{tabular}

This table reports OLS and 2SLS estimates of postponing retirement on the cause-specific health indexes. Excluded instruments in the 2SLS estimation are five interactions between cohort 1938-1942 and local government. See Tables 3 and 4 for more information on the sample of analysis and controls. Robust standard errors in parentheses. $* * *, * *$, $*$ denote statistical significance at the 1,5 , and $10 \%$ levels, respectively

\section{Conclusion}

I have empirically studied the consequences of a 2-year increase in the normal retirement age for Swedish local government workers on subsequent health. Before the reform, which took place in 2000, the age at which the affected workers could claim full benefits was 63. Because the new rules applied to individuals born in 1938 or later, I use birth cohort variation for identification. To control for secular trends in schooling, health care technology and general period effects I use female private sector workers as the control group. The analysis is restricted to women because there were very few men in the largest worker categories that were affected by the reform, which include personal care-related workers, nursing professionals, cleaners and restaurant service workers. These occupations belong to the most common occupations for women both in Sweden and many other European countries.

Health outcomes are measured using detailed individual-level administrative data on drug prescriptions, hospital admissions, and mortality. I focus on the extensive and intensive margin of health care utilization, i.e., the prevalence and total utilization of inpatient care and drug prescriptions during a pre-specified period of time. I study the effect on individuals' drug prescriptions between 2005 and 2009, hospital admissions between ages 65 and 68 and mortality by age 69 .

The results show that the reform increased the actual retirement age by 4.5 months, on average. More importantly, the results show that the reform had no impact on the overall utilization of health care, nor on mortality. The results are supported by several robustness tests and are also similar for the group of compliers (those who actually work longer due to the reform). The zero result applies to several cause-specific health indexes as well with one exception; the probability of being treated for cerebrovascular disease (stroke) decreased as a result of the reform. This result suggests that continued work at older ages may provide individuals with better 
opportunities to preserve a healthy lifestyle than retirement. However, because there is no direct effect on diabetes and alcohol/tobacco related diseases, this result should be interpreted with caution.

The findings of this paper have timely and direct policy implications. The results suggest that raising retirement age thresholds would not have a serious impact on short- to medium-term health outcomes. The external validity of the results could very well be questioned given that we focus on Swedish women in low- to mediumpaid public sector jobs. Although a select group, the features of their pension are similar to those of many other sector-specific pension plans. Moreover, since various discussions of increasing the retirement age thresholds deal primarily with the concern that such increases could adversely affect individuals in low-skilled jobs, this focus could also be considered a strength. To gain insight into to what extent the results can be generalized to male workers we turn to previous studies. Among the studies reviewed in Table 12 that investigate gender heterogeneity, a majority find no significant differences in health outcomes between men and women. Moreover, studies that use a reform-based approach suggest that the potential gender differences are likely to be small or even zero (see, e.g., Hernaes et al. 2013; Atalay and Barrett 2014; de Grip et al. 2012). A similar picture is acquired from the related literature on the health effects of job loss. Using data on all establishment closures in Sweden in 1987 and 1988, Eliason and Storrie (2009b) find no considerable gender disparities in the health effects of job loss. The point estimates for mortality also indicate a similar (positive) impact for both sexes (Eliason 2014).

The result that postponing retirement has no effect on the overall utilization of health care contrasts the general result from studies that study the health effects of targeted early retirement offers. In a related paper that uses similar data on hospital admissions as this paper does, Hallberg et al. (2015) report that the introduction of a generous early retirement program for Swedish army employees reduced the number of days in hospital between ages 61 and 70 by more than $40 \%$. That the results differ might at first not appear surprising given the characteristics of the populations of interest. Female local government workers might simply deal with retirement in a fundamentally different way than male army employees. However, even if we would concentrate on a uniform group of workers, the health implications of targeted early retirement offers may still be different from those of strengthened financial incentives to work longer as workers who retire as soon as they are eligible to claim a pension are likely to be different from those who continue to work until the age at which they can claim a full pension. This could explain why Atalay and Barrett (2014), who study the health effects of increasing women's early eligibility age in Australia, find evidence in line with the studies that look at early retirement offers. One should therefore be careful when using evidence from reforms that affect the early eligibility age to evaluate the potential health effects of measures that prolong the careers of older workers, and vice versa.

Acknowledgments I thank James Poterba, Sören Blomquist, Håkan Selin, Mårten Palme, Karin Edmark, Helena Svaleryd, Anders Björklund, Fan Yang Wallentin, Sergio S. Urzua, Josef Zweimüller, Hannes Malmberg, Matthew Zaragoza-Watkins, Ludovica Gazze, Daan Streuven, Kathleen Easterbrook, Bart Zhou Yueshen, Ponpoje Porapakkarm, Johan Wikström, Per Engström, Arizo Karimi, Daniel Waldenström, Per Johansson, Adrian Adermon, Daniel Hallberg, and seminar participants at IIPF 2015, IFAU, 
Sudswec, Uppsala University, Jönköping University and the Interdisciplinary Workshop on Ageing and Health in Uppsala for their comments. Special thanks to two anonymous referees of Journal of Population Economics whose comments and suggestions helped improve and clarify this manuscript. Financial support from the Jan Wallander and Tom Hedelius Foundation and Forte (DNR 2013-2482) is gratefully acknowledged. The title of an earlier version of this paper is "What are the health effects of postponing retirement? An instrumental variable approach."

\section{Compliance with Ethical Standards}

Conflict of interest The author declares that he has no conflict of interest.

Funding This study was funded by Jan Wallander and Tom Hedelius Foundation (grant number P20130025:1).

Open Access This article is distributed under the terms of the Creative Commons Attribution 4.0 International License (http://creativecommons.org/licenses/by/4.0/), which permits unrestricted use, distribution, and reproduction in any medium, provided you give appropriate credit to the original author(s) and the source, provide a link to the Creative Commons license, and indicate if changes were made.

\section{Appendix}

Table 11 Aggregation of ICD and ATC classifications to create cause-specific health indexes

\begin{tabular}{|c|c|c|}
\hline & $\begin{array}{l}\text { Hospitalization } \\
\text { and mortality (ICD-10) }\end{array}$ & Drug prescription (ATC) \\
\hline Ischemic heart disease & I20-I25 & \\
\hline Hypertension & I10-I15 & \\
\hline Heart disease & & $\mathrm{C} 01, \mathrm{C} 02, \mathrm{C} 03, \mathrm{C} 04, \mathrm{C} 07, \mathrm{C} 08, \mathrm{C} 09, \mathrm{C} 10$ \\
\hline Cerebrovascular & I60-I69 & B01 \\
\hline $\begin{array}{l}\text { Musculoskeletal / } \\
\text { Analgesics }\end{array}$ & M & A03D,A03EA,M01,M02A,M03 \\
\hline Diabetes type 2 & E10-E14 & A10 \\
\hline Alcohol \& tobacco & $\begin{array}{l}\text { C0-C16,C22,C25,C30-C34,C53, } \\
\text { C64-C65,C67,C92.0,C92.4,C92.5, } \\
\text { E24.4, F10, G31.2, G62.1, G72.1, } \\
\text { I42.6, K29.2, K70, K85.2, K86.0, } \\
\text { T51, X45, X65, Y15 }\end{array}$ & \\
\hline \multicolumn{3}{|l|}{ Mental health } \\
\hline Antipsychotics & & N05A \\
\hline Anxiety & & N05B \\
\hline Hypnotics \& sedatives & & N05C \\
\hline Antidepressants & & N06A \\
\hline
\end{tabular}

This table describes the aggregation of the World Health Organization's International Classification of Diseases (ICD) diagnoses and ATC Anatomic Classsification Codes (ATC) codes into common and hypotheses-based causes 


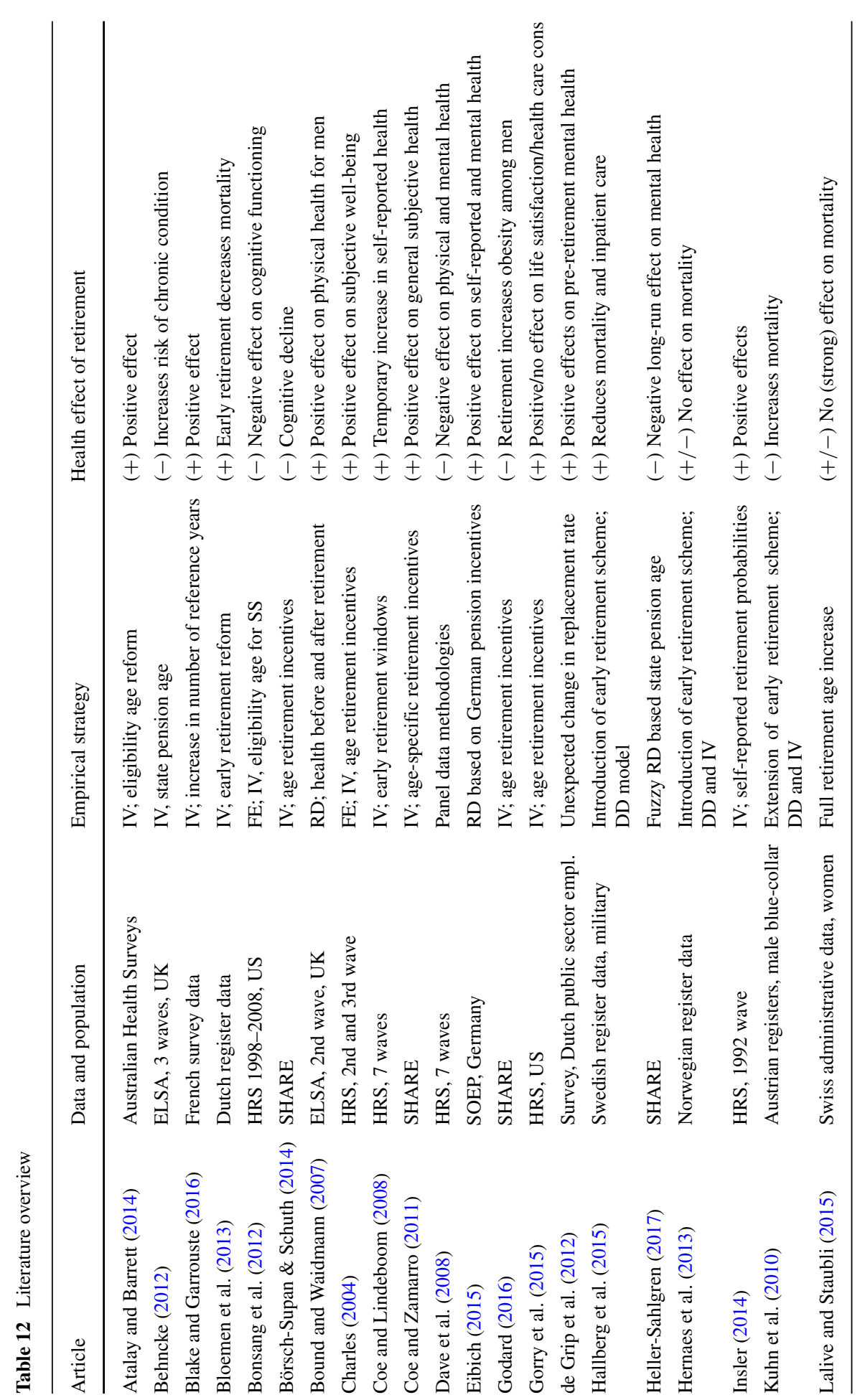




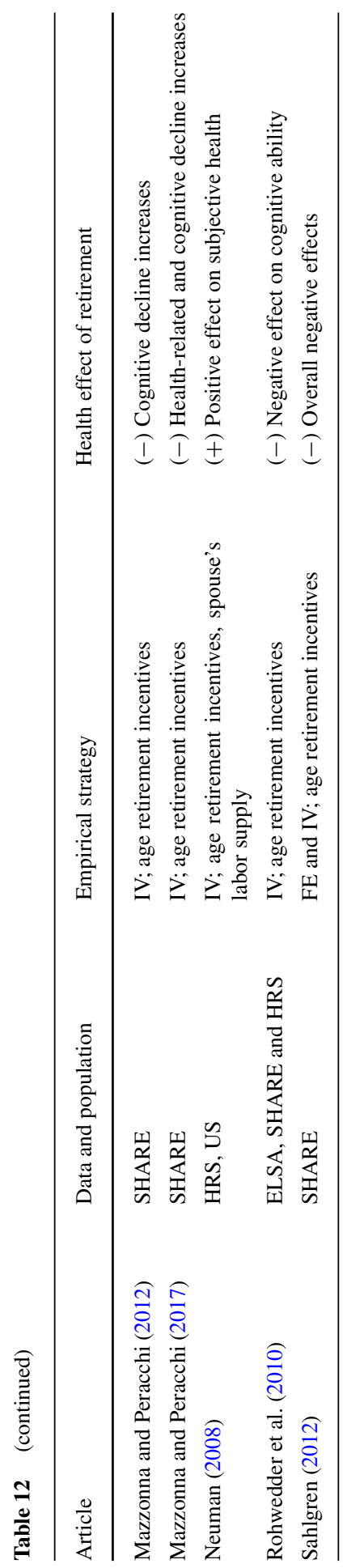


Table 13 The effect of the reform on alternative retirement definitions

\begin{tabular}{|c|c|c|c|c|}
\hline & \multicolumn{2}{|l|}{ Claim age } & \multicolumn{2}{|c|}{ Income-based } \\
\hline & (1) & (2) & (3) & (4) \\
\hline Post-reform $\mathrm{CH} * \mathrm{LG}$ & $\begin{array}{c}0.493^{* * *} \\
(0.0252)\end{array}$ & & $\begin{array}{c}0.365^{* * *} \\
(0.0256)\end{array}$ & \\
\hline Cohort $1938 *$ LG & & $\begin{array}{c}0.223^{* * *} \\
(0.0397)\end{array}$ & & $\begin{array}{c}0.198^{* * *} \\
(0.0404)\end{array}$ \\
\hline Cohort $1939 *$ LG & & $\begin{array}{c}0.397^{* * *} \\
(0.0388)\end{array}$ & & $\begin{array}{c}0.268^{* * *} \\
(0.0403)\end{array}$ \\
\hline Cohort $1940 *$ LG & & $\begin{array}{c}0.586^{* * *} \\
(0.0370)\end{array}$ & & $\begin{array}{c}0.464^{* * *} \\
(0.0393)\end{array}$ \\
\hline Cohort $1941 *$ LG & & $\begin{array}{c}0.604^{* * *} \\
(0.0364)\end{array}$ & & $\begin{array}{c}0.419^{* * *} \\
(0.0395)\end{array}$ \\
\hline Cohort $1942 *$ LG & & $\begin{array}{c}0.615^{* * *} \\
(0.0349)\end{array}$ & & $\begin{array}{c}0.446^{* * *} \\
(0.0385)\end{array}$ \\
\hline Controls & Yes & Yes & Yes & Yes \\
\hline Observations & 133,026 & 133,026 & 133,026 & 133,026 \\
\hline Mean dep. var. & 63.880 & 63.880 & 63.880 & 63.880 \\
\hline F-statistic & 384.359 & 101.839 & 202.792 & 49.333 \\
\hline
\end{tabular}

Dependent variable: income-based retirement age, columns (1)-(2); claim age, columns (3)-(4). Estimated using OLS. Dependent variables right-censored at age 68. Columns (1) and (3) show estimates from Eq. 2 and columns (2) and (4) from Eq. 3. See Tables 3 and 4 for more information on the sample of analysis and controls. Robust standard errors in parentheses. ***, **, * denote statistical significance at the 1, 5, and $10 \%$ levels, respectively

\section{A.1 Differential trends in work environment}

One potential threat to the parallel trends assumption is if the reform coincides with differential trends in occupation-specific work environment. One concern for the existence of differential trends in work environment between public sector and private sector occupations is the large scale retrenchment of the public sector that followed the financial crisis that unfolded in the early 1990s (Angelov et al. 2011). While the effect on private sector employment was large and immediate, the effect on public sector employment was more protracted (Lundborg 2001). If the work environment deteriorated across cohorts in the treatment group as a result of this, and there was no corresponding decline in the control group, we might capture effects on post-retirement health that are not only due to continued work, but to changes in work environment, too. 
I do two things to investigate this issue. First, I look at occupation-specific sick leave patterns for women around the reform. Using data from the Social Insurance Agency, the upper panel of Fig. 5 plots the fraction of female workers that were absent from work for more than 60 days in a given year for five important worker categories. Personal care workers, the most numerous worker category in the treatment group, exhibit much higher absence rates than the other worker categories, but the trends look similar. The trends are also similar when we look at the average number of sick leave days, as can be seen from the lower graph in Fig. 5.

Second, I compare sick leave patterns of younger workers in the treatment and control group occupations in the years surrounding the reform. The advantage of this approach is that younger local government workers' sick leave patterns should be unrelated to the pension reform itself, yet indicative of the work environment situation. For each year between 1996 and 2005, I sample all women aged 45-50 who are either observed working in any of the treatment group occupations listed in Table 1 or in the private sector. Here, an individual is defined as working in the private sector if she is neither self-employed nor working in the public sector. Figure 6 plots the fraction of individuals with more than 14 consecutive days of sick leave in each of these two groups. Re-assuringly, we see that the sickness absence rates evolve similarly both in the years prior to and after the reform.
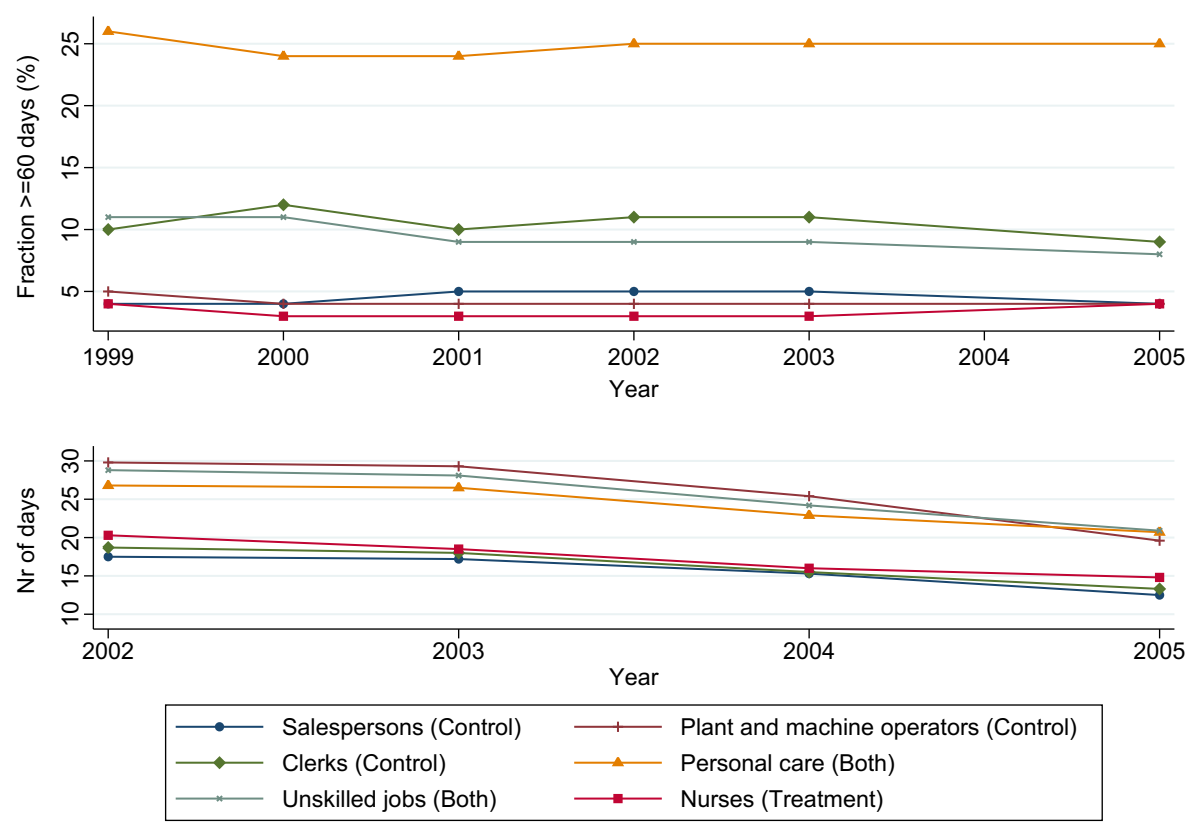

Fig. 5 Sick leave patterns by occupation. The upper figure plots the fraction of female workers with more than 60 sick leave days, by year and occupation. The lower figure plots the average number of sick leave days. The data includes all employed female workers in the age group 18-64. "Unskilled jobs" refer to SSYK codes 91-93. The SSYK codes for the remaining occupations are provided in Table 1. Source: (Försäkringskassa 2012, 2015) 


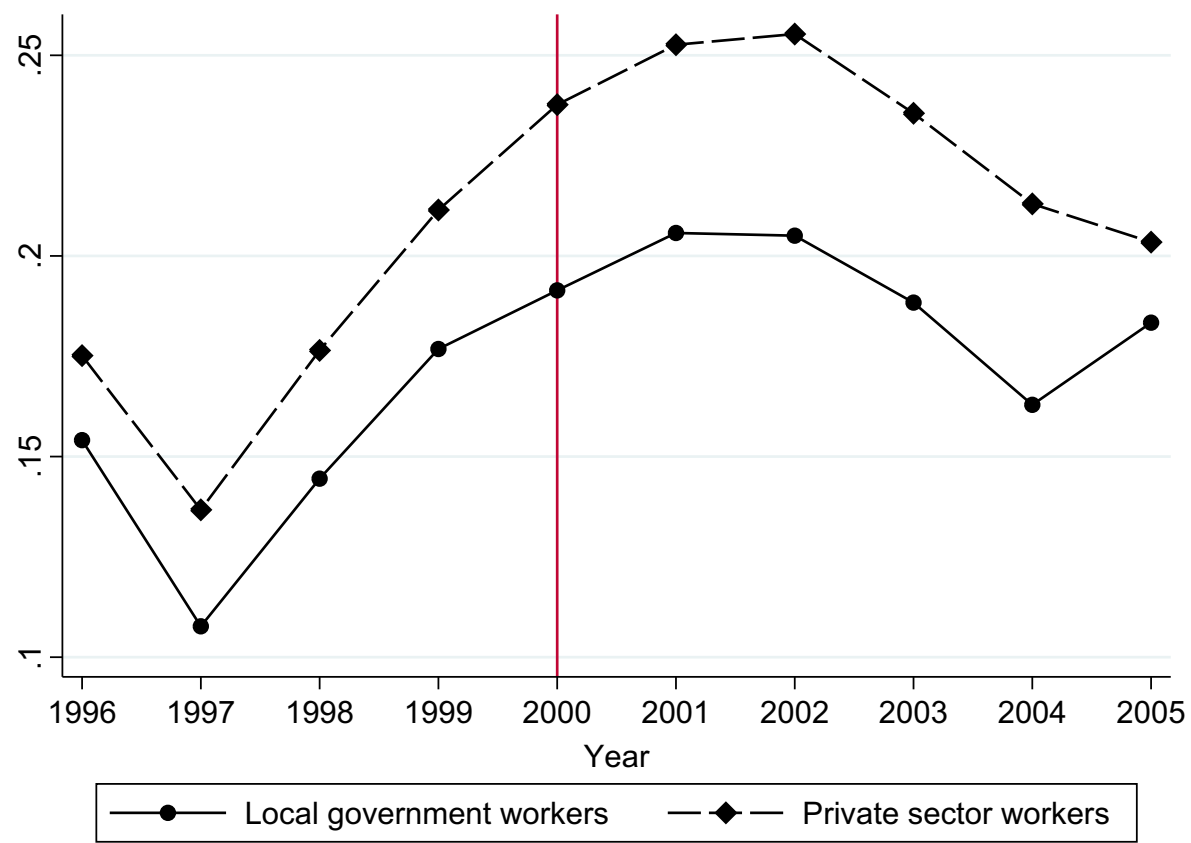

Fig. 6 Sick leave patterns of younger workers. This figure plots the fraction of female workers aged 4550 with more than 14 consecutive days of sick leave for several years surrounding the reform. The solid and dashed lines denote individuals observed working in any of the treatment group occupations (see Table 1) and in the private sector, respectively. The dip in 1997 is the result of a temporary increase in the number of consecutive days an employee had to be sick in order to receive sickness benefits from the Social Insurance Agency rather than the employer. Between January 1, 1997 and March 31, 1998, the 14day period was extended to 28 days. Since employer-provided sickness benefits are not observed in the data, sickness rates are lower during this period by definition

\section{A.2 Robustness tests}

I conducted a number of sensitivity analyses of the main findings. First, I check whether the hospitalization and prescription results are robust to including individuals who died during the follow-up period. Second, I exclude individuals born in 1938 and 1939 who had the possibility of avoiding the new pension rules by retiring early (see Section 5.2). If individuals in bad health truly retired early in order to avoid the new rules, there is an overrepresentation of healthy individuals in the 1938 and the 1939 cohorts in the treatment group which could explain why we find non-negative health effects of postponing retirement. Third, I test whether the results are sensitive to the exclusion of control variables. The results for the main health outcomes and the cause-specific health indexes are presented in Tables 14 and 15, respectively.

Re-assuringly, the two former tests produce results that are very similar to the main results. Excluding the control variables has an impact on two health outcomes; the probability of being prescribed a non-zero quantity of any drug, which is now 
Table 14 Robustness tests of main results

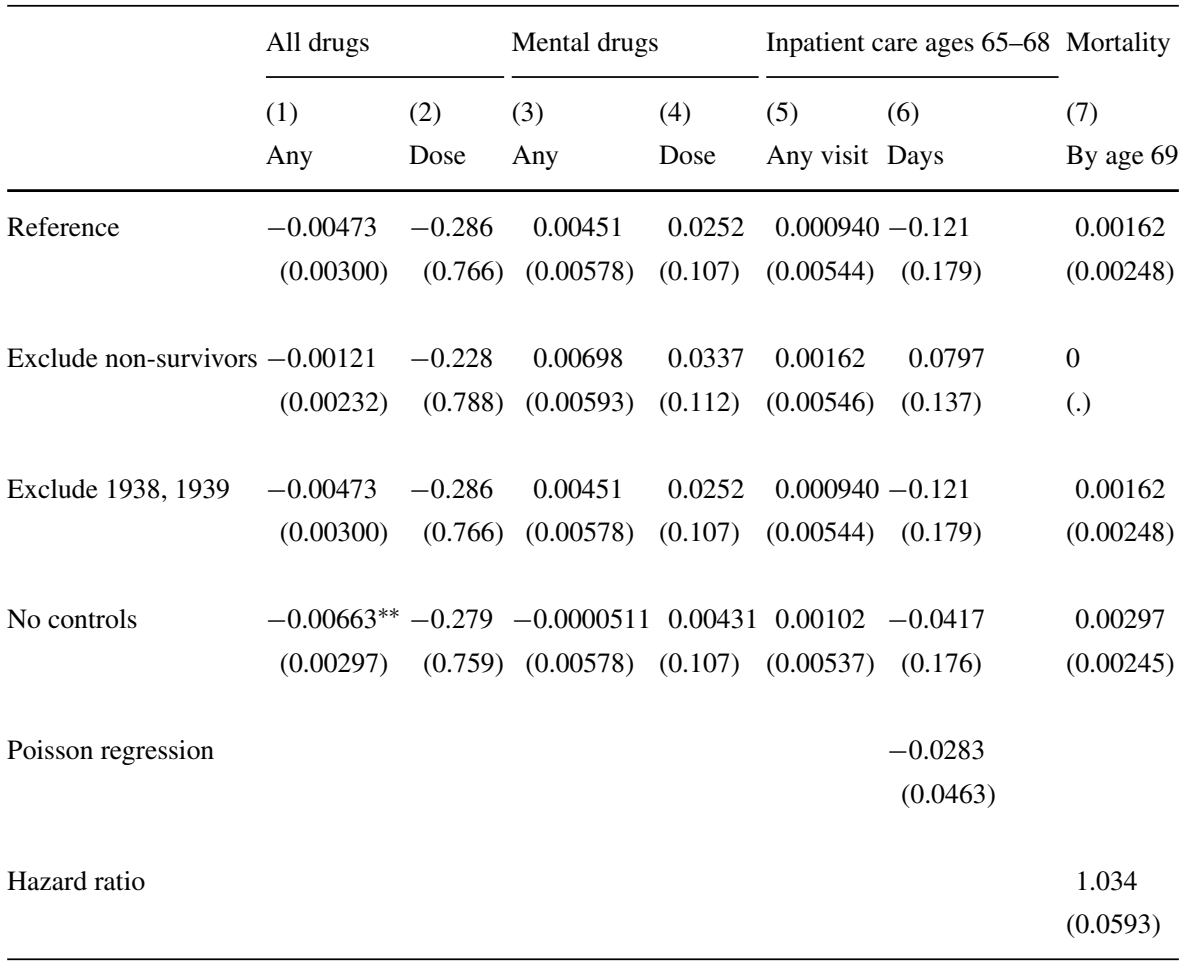

Robustness tests for main health outcomes. Row (1) replicates the main results; row (2) excludes nonsurvivors; row (3) excludes those born in 1938 and 1939 (transition cohorts); row (4) is estimated without controls; row (5) uses Poisson regression for the number of hospital days; row (6) uses a Cox proportional hazard model. See Tables 3 and 4 for more information on the sample of analysis and controls. Robust standard errors in parentheses. $* * *, * *, *$ denote statistical significance at the 1,5 , and $10 \%$ levels, respectively

negative and significant, and the health index related to cerebrovascular disease, which is now insignificant. However, the magnitude of the point estimates are fairly similar to the main estimates and the remaining health outcomes are not sensitive to the exclusion of controls.

Table 14 includes two additional robustness tests. First, column (6) reports the effect on the number of hospital days using Poisson regression. Binomial regression is more appropriate than OLS when the outcome variable is a count variable, i.e., restricted to be positive and also right-skewed. Second, to verify that the insignificant results for mortality do not merely result from the linear probability framework, I supplement the analysis with an estimate from a duration model. Column (7) reports the hazard ratio of the reform on the conditional probability of dying, based on a discrete-time Cox regression model. Both tests yield results that are similar to the main results. 
Table 15 Robustness tests, cause-specific health index

\begin{tabular}{lccccc}
\hline & Heart & Stroke & Musculoskeletal & Lifestyle & Mental health \\
\hline Reference & -0.00343 & $0.0107^{*}$ & -0.000130 & 0.00376 & 0.00318 \\
& $(0.00529)$ & $(0.00638)$ & $(0.00555)$ & $(0.00537)$ & $(0.00502)$ \\
& & & & \\
Exclude non-survivors & -0.00253 & $0.0140^{* *}$ & -0.00343 & 0.00324 & 0.00158 \\
& $(0.00500)$ & $(0.00595)$ & $(0.00537)$ & $(0.00435)$ & $(0.00517)$ \\
Exclude 1938, 1939 & -0.00296 & $0.0124^{*}$ & -0.00311 & 0.00116 & 0.00395 \\
& $(0.00575)$ & $(0.00683)$ & $(0.00606)$ & $(0.00584)$ & $(0.00546)$ \\
No controls & & & & & \\
& & & & & \\
& $(0.00523)$ & $(0.00626)$ & $(0.00552)$ & $(0.00524)$ & $(0.00503)$ \\
\hline
\end{tabular}

Robustness tests for cause-specific health indexes. Row (1) replicates the main results; row (2) excludes non-survivors; row (3) excludes those born in 1938 and 1939 (transition cohorts); row (4) is estimated without controls. See Tables 3 and 4 for more information on the sample of analysis and controls. Robust standard errors in parentheses. $* * *, * *, *$ denote statistical significance at the 1, 5, and $10 \%$ levels respectively

\section{A.3 Heterogeneous treatment effects}

This section analyzes whether the reform differentially affected different types of workers. Figures 7 and 8 plot difference-in-difference estimates and the corresponding $95 \%$ confidence intervals of the effect of the reform on the cause-specific health indexes and mortality by age 69 . Consequently, the effect is not significant at the $5 \%$ level if the confidence interval includes zero. I report $p$ values from an interaction model that test whether the estimated difference between two subsamples is statistically significant. Specifically, I re-estimate the difference-in-difference Equation (1) and interact each right-hand side variable with a dummy for belonging to a certain subsample. The $p$ value of the interaction term between the group dummy variable and the DD estimator then indicates whether the reform had a differential impact on the two groups.

I first estimate the model separately for individuals with income below and above the median of pre-retirement income. Individuals with low income are more likely to have had more physically demanding jobs than individuals with high income. Retiring from such jobs may imply a larger reduction in work-related strain and better health outcomes. ${ }^{21}$ However, for many individuals, work-related activities may constitute the primary form of exercise and physical activity. If the prevalence of

\footnotetext{
${ }^{21}$ For example, Hallberg et al. (2015) find stronger positive health effects of early retirement for workers with low education and low income. Eibich (2015) reports that the positive effect on physical health is stronger among individuals who retire from physically demanding jobs.
} 


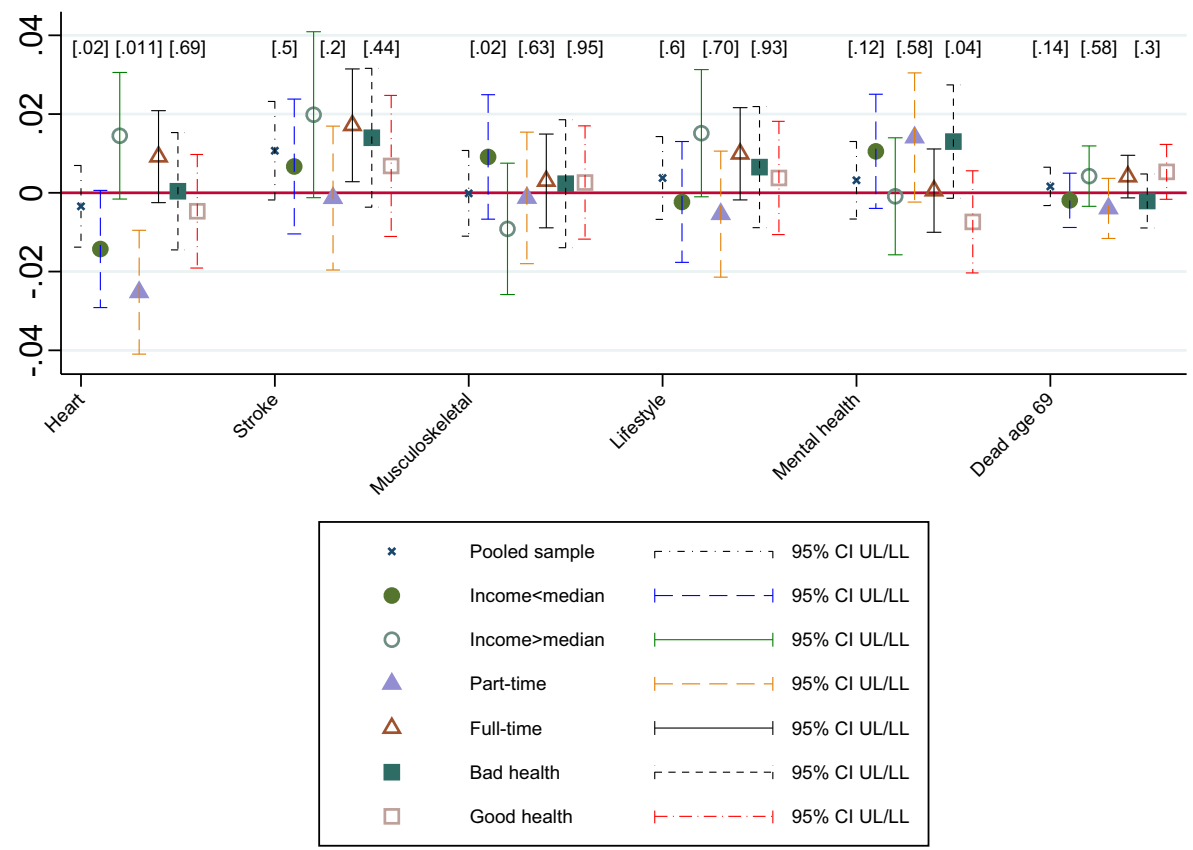

Fig. 7 Effect heterogeneity by income, work amount and health. The figure shows the difference-indifference estimates for the effect of the reform on the cause-specific health indexes and mortality by income level and health status. The dots mark the point estimates and the lines provide $95 \%$ confidence intervals. The brackets above each health outcome report $p$-values from an interaction model that tests the equality of the coefficients between two subsamples

engagement in physical activity is similar or lower for individuals with physically demanding jobs, retirement could lead to more adverse health effects for these workers. ${ }^{22}$ Continued work would then help preserve the health of individuals with demanding occupations.

The results show that there is some effect heterogeneity along the income dimension. Two out of six coefficients are statistically significant from zero, but there is no clear pattern which group fares better than the other. While low-income individuals have significantly better outcomes with respect to musculoskeletal disease, they fare worse in terms of heart disease. One interpretation of this result could be that continued physical activity benefits individuals in low-paid jobs more, but at the same time put them at increased risk of having heart problems. These differences cannot be attributed to differences in labor supply responses to the reform as indicated by Table 5.

Next, I investigate effect heterogeneity with respect to work amount (full-time vs part-time). I classify local government workers as working full-time if they are observed working more than $75 \%$ between ages 61 and 63 (otherwise part-time).

\footnotetext{
${ }^{22}$ For example, Dave et al. (2008) find that the overall negative effect of retirement on health is larger for individuals with physically demanding work.
} 


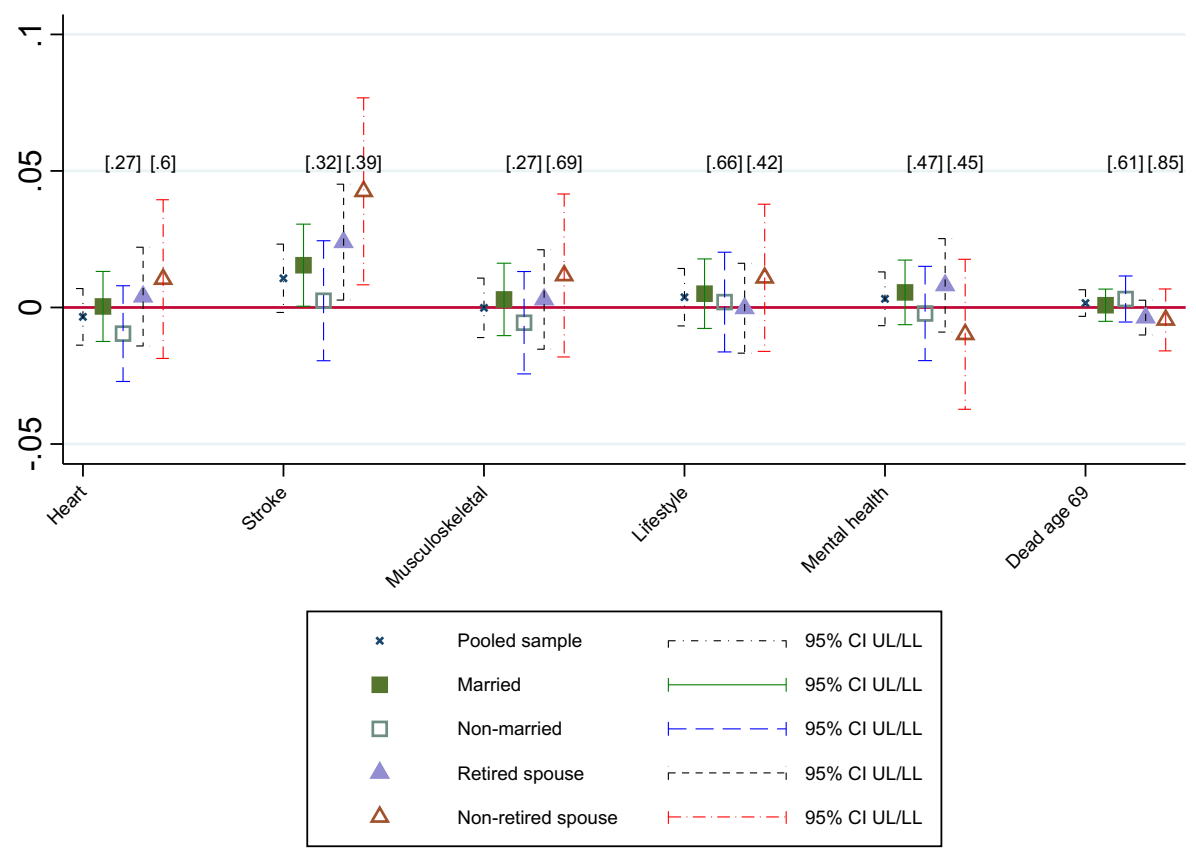

Fig. 8 Effect heterogeneity by marital status. The figure shows the difference-in-difference estimates for the effect of the reform on the cause-specific health indexes by marital status. The brackets above each health outcome report $p$ values from an interaction model that tests the equality of the coefficients between two subsamples

Because information on part-time/full-time work for private sector workers is limited, I include all private-sector workers in the regressions.

Only one health outcome shows significant effect heterogeneity by work amount: part-time workers are more likely to be treated for heart-related disease as a result of the reform compared to full-time workers. We know from the complier analysis in Table 5 that any differential effect on health is unlikely to be driven by differences in labor supply response to the reform.

I also check for effect heterogeneity with respect to ex-ante health status. Individuals in bad health might suffer more if the existing health problems accelerate the health decline that follows from additional work. However, if individuals in bad health have less opportunity to invest in their health after retirement, they might benefit more from continued work relative to individuals with better ex-ante health status. My measure of ex-ante health status is based on whether the individual was on sick leave for at least 14 consecutive days in any year between ages 56 and 60. Based on this definition, close to $50 \%$ are classified into each subsample.

Figure 7 provides little evidence of effect heterogeneity by pre-retirement health status. In most cases, the differences are quite small and also statistically insignificant. Moreover, even if the two mortality estimates have the opposite sign, none of them, as well as the difference between them, are statistically different from zero. Only the difference with respect to mental health is significant. Individuals in bad 
ex-ante health are prescribed less mental health drugs due to the reform compared to individuals in good health.

Finally, the health effects of continued work could also depend on marital status. Social support from a spouse may help to buffer various shocks associated with retirement, diminished social interactions in particular. ${ }^{23}$ Furthermore, married individuals may obtain greater pleasure from retirement than non-married individuals if there is complementarity of leisure between spouses. Continued work should then be more beneficial for non-married than married individuals. However, the opposite case is also conceivable. Increasing the normal retirement age essentially implies that individuals have to work longer to achieve the same pension level. Receiving news about such a reform at short notice could cause mental stress, which may be better dealt with in the presence of a spouse. I also look at heterogeneity with respect to the retirement status of the partner. ${ }^{24}$

The results from estimating the sample separately for married and non-married individuals, and separately for married individuals with and without a retired partner are shown in Fig. 8. As for marital status, the estimates for married individuals reflect better health outcomes. However, $p$ values from the interaction model imply that the two groups do not differ significantly with respect to any outcome. The differences in health outcomes with respect to the retirement status of the partner are also insignificant.

\section{References}

Andersen TM, Määttänen N, Valkonen T (2014) Pension reforms: longevity and retirement. In: Valkonen T, Vihriälä V (eds) The Nordic model - challenged but capable of reform. Nordic Council of Ministers, Copenhagen, pp 113-144

Angelov N, Johansson P, Lindahl E, Lindström E-A (2011) Kvinnors och mäns sjukfrånvaro. IFAU rapport 2011:2

Angrist JD, Pischke J-S (2008) Mostly harmless econometrics: an empiricist's companion. Princeton University Press

Atalay K, Barrett GF (2014) The causal effect of retirement on health: new evidence from Australian pension reform. Econ Lett 125(3):392-395

Behncke S (2012) Does retirement trigger ill health? Health Econ 21(3):282-300

Black SE, Devereux PJ, Salvanes KG (2012) Losing heart? The effect of job displacement on health NBER working paper 18660

Blake H, Garrouste C (2016) Collateral effects of a pension reform in France. Document de travail LEDaLEGOS, Paris, p 58

Bloemen H, Hochguertel S, Zweerink J (2013) The causal effect of retirement on mortality: evidence from targeted incentives to retire early. IZA discussion paper 7570

\footnotetext{
${ }^{23}$ For example, Dave et al. (2008) find that the adverse health effects of retirement are mitigated if the individuals is married.

${ }^{24}$ The retirement status of the partner is based on the year in which the wife retires. Because the LOUISE data only covers individuals aged 16-65 during the period 1987-2000 and individuals aged 16-74 from 2001 and onwards, the information on retirement status of the partner is incomplete for married women who retire prior to year 2001 and whose husbands are born in 1934 or earlier. As a result, I only observe the retirement status of the partner for $82 \%$ of the married workers in the sample.
} 
Bonsang E, Adam S, Perelman S (2012) Does retirement affect cognitive functioning? J Health Econ 31(3):490-501

Börsch-Supan A, Schuth M (2014) Early retirement, mental health, and social networks. Discoveries in the Economics of Aging 225

Bound J, Waidmann T (2007) Estimating the health effects of retirement. Working paper 2007-168. University of Michigan, Michigan Retirement Research Center

Cesarini D, Lindqvist E, Östling R, Wallace B (2015) Wealth, health and child development: evidence from administrative data on Swedish lottery players. Q J Econ. Forthcoming

Charles KK (2004) Is retirement depressing? Labor force inactivity and psychological well-being in later life. Res Labor Econ 23:269-299

Coe N, Lindeboom M (2008) Does retirement kill you? Evidence from early retirement windows. CentER discussion paper 2008-93

Coe NB, Zamarro G (2011) Retirement effects on health in Europe. J Health Econ 30(1):77-86

Dave D, Rashad I, Spasojevic J (2008) The effects of retirement on physical and mental health outcomes. South Econ J 75(2):497-523

de Grip A, Lindeboom M, Montizaan R (2012) Shattered dreams: the effects of changing the pension system late in the game*. Econ J 122(559):1-25

Eibich P (2015) Understanding the effect of retirement on health: mechanisms and heterogeneity. J Health Econ 43:1-12

Eliason M (2014) Alcohol-related morbidity and mortality following involuntary job loss: evidence from swedish register data. J Stud Alcohol Drugs 75(1):35-46

Eliason M, Storrie D (2009a) Does job loss shorten life? J Hum Resour 44(2):277-302

Eliason M, Storrie D (2009b) Job loss is bad for your health-Swedish evidence on cause-specific hospitalization following involuntary job loss. Soc Sci Med 68(8):1396-1406

Feldstein M, Siebert H (2009) Social security pension reform in Europe. University of Chicago Press, Chicago

Försäkringskassan (2012) Sjukskrivningar i olika yrken under 2000-talet. Antal ersatta sjukskrivningsdagar per anställd 2002-2010. Sjukförsäkringsrapport 2012:14. http://www.forsakringskassan.se/ wps/wcm/connect/53a6e173-bad8-4ee2-84df-d909665bfc13/socialforsakringsrapport_2012_14.pdf? MOD=AJPERES

Försäkringskassan (2015) Sjukskrivningar 60 dagar eller längre. en beskrivning av sjukskrivna åren 1999-2014 efter kön, ålder, arbetsmarknadsstatus, yrke, sjukskrivningslängd och diagnospanorama. Socialförsäkringsrapport 2015:1. https://www.forsakringskassan.se/wps/wcm/connect/ d7d4b78e-39fa-4c2f-bed9-ade979b5ff23/socialforsakringsrapport_2015_1.pdf?MOD=AJPERES

Gelber AM, Jones D, Sacks DW (2013) Earnings adjustment frictions: evidence from the social security earnings test. NBER working paper 19491

Godard M (2016) Gaining weight through retirement? Results from the SHARE survey. J Health Econ 45:27-46

Gorry A, Gorry D, Slavov S (2015) Does retirement improve health and life satisfaction? NBER working paper 21236

Hagen J (2013) A history of the Swedish pension system. Working Paper 2013:7, Department of Economics, Uppsala University

Hallberg D, Johansson P, Josephson M (2015) Is an early retirement offer good for your health? Quasiexperimental evidence from the army. J Health Econ 44:274-285

Hanel B, Riphahn RT (2012) The timing of retirement-new evidence from swiss female workers. Labour Econ 19(5):718-728

Heller-Sahlgren G (2017) Retirement blues. J Health Econ 54:66-78

Hernaes E, Markussen S, Piggott J, Vestad OL (2013) Does retirement age impact mortality? J Health Econ 32(3):586-598

Holzmann R (2005) Old-age income support in the 21st century: an international perspective on pension systems and reform. World Bank Publications, Washington, DC

Insler M (2014) The health consequences of retirement. J Hum Resour 49(1):195-233

Jensen RT, Richter K (2004) The health implications of social security failure: evidence from the Russian pension crisis. J Public Econ 88(1):209-236

Kreiner CT, Leth-Petersen S, Skov PE (2014) Year-end tax planning of top management: evidence from high-frequency payroll data. Am Econ Rev 104(5):154-158 
Kuhn A, Wuellrich J-P, Zweimuller J (2010) Fatal attraction? Access to early retirement and mortality. IZA discussion paper 5160

Lalive R, Staubli S (2015) How does raising women's full retirement age affect labor supply, income, and mortality? NBER working paper 18660

Laun L (2012) The effect of age-targeted tax credits on retirement behavior. IFAU working paper 2012:18

Laun L, Palme M (2017) The recent rise of labor force participation of older workers in Sweden. Mimeo

Lundborg P (2001) Konjunktur-och strukturproblem i 90-talets arbetslöshet. Ekonomisk debatt 29(1):7-18

Manoli D, Weber A (2014) Nonparametric evidence on the effects of financial incentives on retirement decisions. CESifo working paper 4619

Mastrobuoni G (2009) Labor supply effects of the recent social security benefit cuts: empirical estimates using cohort discontinuities. J Public Econ 93(11):1224-1233

Mazzonna F, Peracchi F (2012) Ageing, cognitive abilities and retirement. Eur Econ Rev 56(4):691-710

Mazzonna F, Peracchi F (2017) Unhealthy retirement? J Hum Resour 52(1):128-151

Midanik LT, Soghikian K, Ransom LJ, Tekawa IS (1995) The effect of retirement on mental health and health behaviors: the Kaiser Permanente retirement study. J Gerontol Ser B Psychol Sci Soc Sci 50(1):S59-S61

Moon JR, Glymour MM, Subramanian S, Avendaño M, Kawachi I (2012) Transition to retirement and risk of cardiovascular disease: prospective analysis of the US health and retirement study. Soc Sci Med 75(3):526-530

Neuman K (2008) Quit your job and get healthier? The effect of retirement on health. J Lab Res 29(2):177201

Palme M, Svensson I (2004) Income security programs and retirement in Sweden. In: Gruber J, Wise D (eds) Social security programs and retirement around the world: micro-estimation. University of Chicago Press, Chicago, pp 579-642

Rohwedder S, Willis RJ et al (2010) Mental retirement. J Econ Perspect 24(1):119-38

Ruhm CJ (2000) Are recessions good for your health? Q J Econ 115(2):617-650

Sahlgren G (2012) Work 'til you drop: short-and longer-term health effects of retirement in Europe. IFN working paper 928

Selin H (2017) What happens to the husband's retirement decision when the wife's retirement incentives change? Int Tax Public Financ 24(3):432-458

Socialstyrelsen (2015a) Läkemedel - statistik för år 2014. https://www.socialstyrelsen.se/lists/ artikelkatalog/attachments/19768/2015-3-17.pdf

Socialstyrelsen (2015b) Sjukdomar i sluten vård 1989-2014. https://www.socialstyrelsen.se/lists/ artikelkatalog/attachments/19921/2015-10-1.pdf

Song JG, Manchester J (2007) New evidence on earnings and benefit claims following changes in the retirement earnings test in 2000. J Public Econ 91(3):669-700

Sundén A (2006) The swedish experience with pension reform. Oxf Rev Econ Policy 22(1):133-148

Vahtera J, Westerlund H, Hall M, Sjösten N, Kivimäki M, Salo P, Ferrie J, Jokela M, Pentti J, SinghManoux A et al (2009) Effect of retirement on sleep disturbances: the Gazel prospective cohort study. Sleep 32(11):1459-66

Van Doorslaer E, Wagstaff A, Van der Burg H, Christiansen T, De Graeve D, Duchesne I, Gerdtham U-G, Gerfin M, Geurts J, Gross L et al (2000) Equity in the delivery of health care in Europe and the US. J Health Econ 19(5):553-583

Van Doorslaer E, Koolman X, Jones AM (2004) Explaining income-related inequalities in doctor utilisation in europe. Health Econ 13(7):629-647 